\title{
Entre las restricciones y la creatividad: migrantes y derechos humanos en Sudáfrica y Tanzania*
}

\section{Beatriz Escobar Cristiani** María del Rayo Ventura***}

\section{RESUMEN}

En años recientes, los movimientos migratorios se han consolidado como una preocupación fundamental en el mundo. El discurso oficial de muchos paises subraya el valor de las migraciones, pero con frecuencia la presencia de migrantes genera distintas formas de rechazo e intentos por limitar sus derechos. Los migrantes han tenido que desarrollar diversas estrategias para enfrentar las restricciones y responder a las violaciones a sus derechos. El presente articulo explora la forma en que estas tendencias se han manifestado en el caso específico de dos paises africanos: Sudáfrica y Tanzania. Además, ofrece un análisis comparativo de las experiencias comunes de los migrantes en relación con los derechos humanos y cómo se adaptan a los cambiantes contextos socioeconómicos y políticos en Sudáfrica y Tanzania.

PALABRAS CLAVE: Agencia, empoderamiento, derechos humanos, migrantes, Sudáfrica, Tanzania.

\section{ABSTRACT}

In recent years, migratory movements have been consolidated as a major concern across the world. The official discourse of many countries underlines the value of migrations, but often the presence of migrants generates different forms of rejection and attempts to limit their rights. Migrants have had to develop many strategies to face restrictions and to answer to violations of their rights. This article analyses how these trends have appeared in South Africa and Tanzania. It also provides a comparative study of common experiences of migrants relating to human rights and how they adapt to changing socioeconomic and political contexts in South Africa and Tanzania

KEY WORD: Agency, empowerment, human rights, migrants, South Africa, Tanzania

* Artículo recibido el 23 de Noviembre de 2016 y aceptado el 1 de febrero de 2017.

** Facultad de Ciencias Políticas y Sociales-Universidad Nacional Autónoma de México. (bescoba@yahoo.com)

*** Investigadora independiente residente en Pretoria. (venturama@yahoo.com) 


\section{SUMARIO}

1. Introducción

2. Reflexiones en torno a la xenofobia y la agencia

3. Migración en Sudáfrica y Tanzania: una mirada histórica

4. Xenofobia y restricción de derechos: sus implicaciones para los migrantes

5. Acción de los migrantes: estrategias para el fortalecimiento de la agencia

6. Estrategias en el comercio informal

7. Estableciendo vínculos: migrantes y organizaciones no gubernamentales

8. Manifestaciones públicas

9. Concentración geográfica y preservación de la identidad

10. La agencia bajo control institucional: los campos de refugiados

11. La agencia fuera del radar oficial: refugiados urbanos indocumentados

12. Conclusiones

\section{Introducción}

En los últimos tiempos se ha registrado un explosión informativa sobre la migración. La llegada de refugiados de origen sirio a Europa, el hundimiento de barcos que transportan migrantes africanos en el Mediterráneo o las declaraciones de Donald Trump sobre los trabajadores mexicanos en Estados Unidos se han convertido en elementos constantes de noticieros, periódicos y redes sociales. Esta cobertura informativa refleja una realidad innegable: el movimiento de personas a través de las fronteras internacionales se ha convertido en parte fundamental de un mundo crecientemente globalizado. ${ }^{1}$ Sin embargo, no da cuenta del fenómeno en toda su magnitud y, por el contrario, contribuye a consolidar varias percepciones estereotipadas acerca de los migrantes.

Uno de los estereotipos más extendidos es que los migrantes pueden entrar, básicamente, en una de dos categorías: la de oportunistas que arrebatan los recursos a las poblaciones locales o la de víctimas indefensas que dependen de la buena voluntad internacional. Otro estereotipo es que la migración, en el peor de los casos, es un proceso que desemboca en la muerte de los migrantes o, en el mejor de los escenarios, en su llegada a un país preferentemente desarrollado. Esto, desde luego, dificulta ver que para un migrante la llegada a un país distinto del suyo es apenas el inicio de un proceso continuo de negociación de recursos e identidades.

\footnotetext{
${ }^{1}$ En la actualidad existen más de 215 millones de migrantes internacionales que viven fuera de su país de origen. ONU - OHCHR, Migration and human rights. Improving Human Rights-Based Governance of International Migration. Ginebra, ONU - OHCHR, 2013, pp. 7-8. Disponible en: http://www.ohchr.org/Documents//ssues/Migration/MigrationHR_improvingHR_Report.pdf
} 
Para superar esta imagen incompleta, es necesario analizar el tema de una manera mucho más cuidadosa. La migración debe ubicarse en un marco más amplio, que afecta y, al mismo tiempo, se ve influido por el contexto sociopolítico de los lugares de origen y destino. ${ }^{2}$

El presente artículo analiza las manifestaciones del fenómeno migratorio y su vinculación con el tema de los derechos humanos en dos países africanos, Sudáfrica y Tanzania, desde un enfoque poco tratado en la literatura: los mecanismos que emplean los propios migrantes como estrategias para defender sus derechos en un ambiente hostil. Para ello, se revisa el concepto de xenofobia (fenómeno en ascenso en los dos casos de estudio y en el contexto global) como una limitante a los derechos humanos de los migrantes.

Sin embargo, a fin de entender el fenómeno más allá del ascenso de la xenofobia, se introduce el tema de la capacidad de agencia de los migrantes. Ésta se refleja en la adopción de distintas estrategias para hacer frente a las limitaciones de sus derechos y para tratar de ampliar sus espacios de acción. Finalmente, se analiza cómo esta tensión entre crecientes limitaciones a los derechos de los migrantes y búsqueda de espacios de apertura por parte de estos ha tenido lugar en los casos concretos de Sudáfrica y Tanzania.

Aunque en ambos países el universo de la migración es muy diverso, en el trabajo se analizan dos tipos específicos de migrantes originarios del continente africano: para Sudáfrica, los migrantes económicos que se convierten en comerciantes informales y los refugiados; para Tanzania, los refugiados. Estos grupos constituyen, en lo general, dos de los principales núcleos de migrantes en los países analizados.

\section{Reflexiones en torno a la xenofobia y la agencia}

La protección de los derechos humanos de los migrantes es fundamental para garantizarles mejores condiciones de vida y para aprovechar al máximo los elementos que pueden aportar a las sociedades de origen y destino, así como a la comunidad internacional. No obstante, en los últimos años se ha registrado a nivel mundial una marcada tendencia a restringir esos derechos.

En diversos sentidos, los migrantes son vistos como una anomalía que pone en riesgo la estructura de un mundo dividido en Estados-nación, pues no

\footnotetext{
${ }^{2}$ Landau, Loren, "Beyond the Losers: Transforming Governmental Practices in Refugee Affected Tanzania", Journal of Refugee Studies, vol. 16, núm. 1, 2003, p. 20.
} 
pertenecen plenamente ni a un lugar (el de partida) ni a otro (el de llegada). ${ }^{3}$ Por la misma razón, el migrante se vuelve alguien marginal, que se encuentra en un espacio liminal caracterizado por "la carencia". El migrante carece, desde este punto de vista, de un hogar, de una voz y de un rostro.

El Estado realizará continuamente esfuerzos para identificar al extraño y aislarlo, separarlo claramente del yo colectivo que representa la nación. Este proceso de señalar al otro contribuirá de manera importante a la definición del yo estatal-nacional. La operación se lleva a cabo de distintas maneras, llegando incluso a elevados niveles de violencia en contra del extranjero. ${ }^{4}$ Esto es lo que se conoce como xenofobia.

Cea señala que existen tres parámetros generales que pueden ayudar al análisis de la problemática de la xenofobia. En primer lugar, menciona las condiciones socioeconómicas imperantes, que en épocas de crisis o recesión económica pueden ocasionar la competencia por recursos limitados (empleo, vivienda, etcétera), entre una parte de la población local del país receptor y los migrantes. Un segundo parámetro es el nivel de tolerancia cultural del país receptor, el cual afecta directamente a los migrantes: si es muy bajo se observará rechazo hacia quienes tienen determinado color de piel o una identidad cultural diferente (religión, costumbres, entre otras). En tercer lugar, deben considerarse las condiciones políticas, que establecen el acceso y reparto de recursos del Estado con base en la pertenencia a una determinada identidad colectiva o Estado nación. ${ }^{5}$

Para el caso específico de África, Fourchard y Segatti sostienen que las luchas por la descolonización moldearon los ejercicios de construcción nacional durante el período poscolonial. Esta construcción estuvo continuamente vinculada con el concepto de extraño, entendido como alguien que se percibe como una amenaza para la sociedad o grupo, por lo cual se excluye o hasta se suprime. El concepto de extraño no sólo se refiere a personas de otros países, también incluye a personas de diferentes grupos étnicos y grupos lingüísticos. Por esta razón, los autores citados argumentan que en África el concepto de xenofobia se combina con otros conceptos como la autoctonía, el indigenismo

\footnotetext{
${ }^{3}$ Turner, Simon, "Under the Gaze of the "Big Nations": Refugees, Rumours and the International Community in Tanzania", African Affairs, núm. 103, 2004, p. 229.

${ }^{4}$ Turner, Simon, "Under the Gaze of the "Big Nations": Refugees, Rumours and the International Community in Tanzania", African Affairs, núm. 103, 2004, pp. 229-230.

${ }^{5}$ Cea D'Ancona, Maria Ángeles, "La exteriorización de la Xenofobia", Revista Española de Investigaciones Sociológicas, núm. 112, octubre-diciembre, 2005, pp. 202-207.
} 
y el nativismo. ${ }^{6}$ También juegan un papel central ciertos factores de análisis como la etnicidad, el territorio, el nacionalismo, la propiedad de las tierras ancestrales, entre otros.

El enfoque tradicional para enfrentar los retos que plantea la xenofobia ha sido la promoción de los derechos humanos del migrante por parte de un tercero que no se encuentre en el espacio liminal del migrante, sino en el marco "normal" del Estado-nación (normalmente, organizaciones ya sea gubernamentales o no gubernamentales, nacionales o internacionales). En esta perspectiva, los migrantes son considerados entes pasivos, que deben esperar la ayuda de los actores internacionales mejor posicionados. Esta imagen coincide con la que muestran los medios: los migrantes como un miserable océano de personas que requieren un flujo constante de ayuda. ${ }^{7}$

Esta imagen no corresponde con la realidad. En los hechos, los migrantes son simplemente sujetos que enfrentan crecientes restricciones y deben buscar en forma cotidiana vías alternas para actuar de la mejor manera posible en ese contexto. Para entender así la migración, dos conceptos resultan de gran utilidad: agencia y empoderamiento.

El empoderamiento es un proceso para aumentar el poder como resultado de la interacción de dos ejes: la agencia y la estructura de oportunidades. ${ }^{8}$ Para Bakewell, la agencia es la capacidad de los actores sociales de reflexionar sobre su posición, diseñar estrategias y emprender acciones que les permitan alcanzar sus objetivos. Ser un agente significaría entonces tener la capacidad de ejercer cierto grado de control -y tener cierto grado de incidencia- sobre las relaciones sociales en las que nos encontramos inmersos.

Esto puede ocurrir incluso bajo las formas más extremas de coerción. ${ }^{9} \mathrm{La}$ agencia se puede entender también como la capacidad de un actor, o grupo, de realizar elecciones significativas y estaría determinada por los activos que ese actor tiene a su disposición y las capacidades (humanas, sociales o psicológicas) con las cuales cuenta. ${ }^{10}$

\footnotetext{
${ }^{6}$ Fourchard, Laurent y Segatti, Aurela, "Introduction of Xenophobia and Citizenship: the everyday politics of exclusion and inclusion in Africa", Africa, vol. 85, núm. 1, 2015, p. 2.

${ }^{7}$ MALKKI, LIISA, "Speechless Emissaries: Refugees, Humanitarianism, and Dehistoricization", Cultural Anthropology, vol. 11, núm. 3, 1996, p. 377.

${ }^{8}$ Samman, Emma y Santos, Maria Emma, Agency and Empowerment: A review of concepts, indicators and empirical evidence, Oxford, University of Oxford, 2009, p. 5.

9 BAKEWELL, OLIVER, "Some Reflections on Structure and Agency in Migration Theory", Journal of Ethnic and Migration Studies, vol. 36, núm. 10, 2010, pp. 1694, 1701.

${ }^{10}$ La estructura de oportunidades incluirá aspectos muy variados, desde el acceso a la información hasta el grado de inclusión económica. Véase Samman, Emma y Santos, Maria Emma, Agency and Empowerment: A review of concepts, indicators and empirical evidence, Oxford, University of Oxford, 2009, pp. 3 y 10.
} 
Aparece aquí la otra parte de la ecuación: la estructura de oportunidades. Esta se refiere a los elementos externos, el marco institucional y el contexto social y político que delimitarán las posibilidades de acción de personas y grupos. En última instancia, será esa estructura de oportunidades la que posibilite $-\mathrm{u}$ obstaculice- la eficacia de los distintos actores. Es decir, explicará el grado de empoderamiento de quienes emprenden una acción, entendiendo empoderamiento como la intersección de tres factores: la oportunidad para hacer una elección, la posibilidad de llevar a la práctica esa elección y la obtención de los resultados deseados. ${ }^{11}$

Como se puede observar, la agencia y el empoderamiento no son sólo algo personal, asociado a la mera voluntad. Quedarse en este primer nivel, el del sentido de empoderamiento, sería un error. ${ }^{12}$ En realidad, los individuos actúan en el marco de una estructura de oportunidades determinada. Tales estructuras delimitan la actuación de personas y grupos, pero estos a su vez pueden también influir en las estructuras. En otras palabras, a través de su agencia, los actores pueden contribuir a transformar en el largo y mediano plazo las propiedades de la estructura, en un proceso continuo de conflicto y negociación entre grupos sociales. Esto muchas veces puede tener efectos distintos de los esperados por un actor determinado. ${ }^{13}$

Por todo ello, la agencia debe considerarse más como un elemento constitutivo de una situación social que como un elemento estrictamente individual. La agencia emerge a través de actores que comparten compromisos con ciertas actividades y que comparten recursos diversos para alcanzar sus metas. Así, constituyen redes sociales de distintos tipos y con varios objetivos, desde familias, grupos de pares, organizaciones, entre otras. ${ }^{14}$ Este juego de factores individuales y sociales se aprecia con claridad al estudiar el fenómeno de la migración. Con frecuencia, distintas prácticas de los migrantes se pueden entender como formas de ganar o conservar agencia en situaciones donde su capacidad de actuación se ve restringida.

\footnotetext{
"Samman, Emma y Santos, Maria Emma, Agency and Empowerment: A review of concepts, indicators and empirical evidence, Oxford, University of Oxford, 2009, p. 4.

${ }^{12}$ Si pensamos en que el empoderamiento se refiere exclusivamente al sentido de control, estaremos haciendo de lo politico un asunto meramente personal. Para Riger, esta trampa con frecuencia se promueve desde la propia estructura del capitalismo, la cual demanda que las personas se consideren agentes libres sin serlo en realidad. Riger, Stephanie, "What's wrong with empowerment", American Journal of Community Psicology, junio de 1993, pp. 280, 282.

${ }^{13}$ BAKEwELL, Oliver, "Some Reflections on Structure and Agency in Migration Theory", Journal of Ethnic and Migration Studies, vol. 36, núm. 10, 2010, p. 1697.

${ }^{14}$ Kongeter, Stefan y Smith, Wendy, "Transnational Agency. Migrants, Movements and Social Support Crossing Borders", en Stefan Kongeter, y Wendy Smith (eds.), Transnational Agency and Migration: Actors, Movements, and Social Support, Nueva York, Taylor and Francis, 2015, p. 7.
} 


\section{Migración en Sudáfrica y Tanzania: una mirada histórica}

Las migraciones no son un fenómeno nuevo en el continente africano. Tanto en Sudáfrica como en Tanzania, a lo largo de la historia, se han registrado numerosos movimientos de población. De hecho, las migraciones han sido una parte integral de la vida social y económica de estos países. En ambos casos, los patrones de migración se han transformado con el tiempo, dependiendo del contexto socioeconómico y político de cada momento.

En Sudáfrica, un ejemplo claro de ello fueron los cambios que provocó el descubrimiento de los minerales en el siglo XIx. Este fenómeno permitió el paso de una economía agrícola hacia una industrial. Esto derivó en una mayor demanda de migrantes no calificados de piel negra, provenientes de la población local e incluso de países vecinos como Angola y Mozambique. ${ }^{15}$

Como resultado, se creó un sistema capaz de garantizar bajos costos a través de dos elementos: las leyes y los mecanismos de reclutamiento. Las leyes, que separaron a los diferentes grupos en torno a líneas raciales, ${ }^{16}$ aseguraron la existencia de mano de obra barata. ${ }^{17}$ Por otro lado, la creación de la South African Chambers of Mines, la Witwatersrand Natives Labour Association (Wenela) y la Native Recruitment Corporation, constituyó la base para obtener mano de obra fuera de las fronteras sudafricanas, en Botsuana, Lesoto, Malaui, Mozambique y Suazilandia. El sistema migratorio se consolidó con la celebración de acuerdos con las autoridades coloniales de los países vecinos -y posteriormente, con los gobiernos surgidos tras la independencia de dichos países-. ${ }^{18}$

\footnotetext{
${ }^{15}$ Crush, Jonathan, "South Africa: Policy in the Face of the Xenophobia", Migration Policy Institute. [Consulta: 15 de octubre, 2016]. Disponible en: http://www.migrationpolicy.org/article/south-africa-policy-face-xenophobia

${ }^{16}$ Blancos (divididos a su vez en quienes hablaban inglés y quienes hablaban afrikáans); coloureds (mestizos); población de origen asiático y población africana.

${ }^{17}$ Una muestra del complejo entramado legal es la Native Land Act de 1936, por medio de la cual se determinó que sólo $13.7 \%$ del territorio podría ser habitado por la mayoría de la población: Ios africanos. Ello confirmó la desposesión material de esta población, que se vio obligada a buscar su subsistencia a través de trabajos mal remunerados. Legassick, Martin, "Gold, Agriculture and Secondary Industry in South Africa", en Palmer y Parson (ed.), The roots of rural poverty in Central and Southern Africa, University of California Press, 1977, p. 180. WA KWABE, AurelA, "Reforming South African immigration policy in the post-apartheid period (1990-2006): what it means and what it takes", Wa Kwabe Segatti y Landau (eds.), Migration in post-apartheid South Africa: Challenges and questions to policy-makers, Research Department Agence Francaise de Developpement, 2008, p. 61. [Consulta: 27 de octubre, 2016]. Disponible en: http://www.afd.fr/jahia/webdav/site/afd/shared/PUBLICATIONS/RECHERCHE/Archives/ Notes-et-documents/38-notes-documents-VA.pdf

${ }^{18}$ Wentzel, Marie y Tlabela, Kholad, Migration in South and Southern Africa. Dynamics and determinants, hSrc Press. [Consulta: 27 de octubre, 2016]. Disponible en: http://www.hsrcpress.ac.za/product.php?productid=2094\&tfreedownload $=1$
} 
En la demanda de trabajadores extranjeros influyeron las coyunturas internas, como la crisis de empleo de 1970, en la cual se dio preferencia a los trabajadores locales. También influyeron factores externos como la guerra civil de Mozambique, episodio que produjo la llegada de refugiados a territorio sudafricano en la década de 1980. El gobierno nunca los reconoció como refugiados y los confinó a algunos espacios destinados a la población africana. Algunos fueron deportados al salir de la zona designada, pero otros migraron en busca de trabajo hacia lo que hoy se conoce como las provincias de Mpumalanga y Gauteng. ${ }^{19}$

La efervescencia política y social y la acción de movimientos de liberación como el African National Congress (ANc), aunada al estancamiento de la economía y al retiro paulatino del apoyo de los capitales extranjeros, hicieron inminente la caída del apartheid. El proceso culminó con la celebración de las primeras elecciones multirraciales en 1994. Esta apertura tuvo repercusiones en las actividades realizadas por los migrantes, pues se observó la llegada de profesionistas de otras partes del continente africano, la incursión de migrantes en actividades comerciales transfonterizas, así como la aparición de migrantes en situación irregular en trabajos diversos (como jardineros, meseros y personal de limpieza). Igualmente, se registró la llegada de refugiados de otras partes de África debido a las condiciones de inestabilidad política y económica de la zona. ${ }^{20}$

En el caso de Tanzania, una característica fundamental del fenómeno migratorio ha sido la llegada masiva de refugiados. Entre 1959 y 1961 comenzaron a llegar al territorio tanzano refugiados tutsis que escapaban de la zona de los Grandes Lagos. Para 1961 había ya más de 10000 refugiados ruandeses. ${ }^{21}$ El Gobierno emprendió un programa de reasentamiento rural que incluía la provisión de tierras para los refugiados y se esforzó también por promover la integración a través de la educación. Esta política se repitió en la década de 1970 con los refugiados provenientes de Burundi, quienes llegaron en un número mayor: en 1972 había en Tanzania 72000 burundeses, y hacia 1974 esta población alcanzaba ya 120000 .

\footnotetext{
19 Wentzel, Marie y Tlabela, Kholadi, Migration in South and Southern Africa. Dynamics and determinants, hSRc Press. [Consulta: 27 de octubre, 2016]. Disponible en: http://www.hsrcpress.ac.za/product.php?productid=2094Etfreedownload $=1$

${ }^{20}$ Crush, Jonathan, "South Africa: Policy in the Face of the Xenophobia", Migration Policy Institute. [Consulta: 15 de octubre, 2016]. Disponible en: http://www.migrationpolicy.org/article/south-africa-policy-face-xenophobia

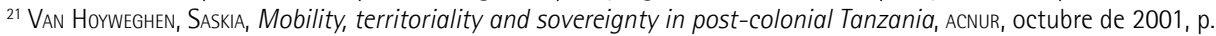
14. Disponible en: http://www.unhcr.org/research/working/3bf101b37/mobility-territoriality-sovereignty-post-colonial-tanzania-saskia-van-hoyweghen.html
} 
De nueva cuenta, la respuesta del Gobierno fue la promoción del reasentamiento, con un marcado énfasis en la promoción de la autosuficiencia y en la explotación de la tierra como una contribución al desarrollo nacional. ${ }^{22}$ Por ello, en esta etapa Tanzania fue considerada un modelo a seguir, por la "excepcional hospitalidad" que se mostró a los refugiados. ${ }^{23}$ Ello se puede entender considerando el modelo de construcción nacional impulsado por Nyerere, basado en la idea de construir una sociedad autosuficiente e igualitaria a través de un socialismo africano, que apoyaba la causa del panafricanismo.

El panorama se transformó en la década de 1990, cuando la apertura política y económica en Tanzania se combinó con una serie de crisis en la región de los Grandes Lagos. En 1989, Nyerere dejó la presidencia y se inauguró un período de liberalización económica y política que implicó el abandono del modelo de socialismo africano. De manera notoria, este proceso coincidió con un contexto de conflicto generalizado a nivel regional, la llegada de grandes números de refugiados al país.

La guerra civil en Burundi, el genocidio en Ruanda y el conflicto en lo que ahora es la República Democrática del Congo derivaron en la llegada de cientos de miles de refugiados al territorio tanzano. Los brotes de violencia en estos países se han repetido intermitentemente, provocando migraciones continuas. De esta manera, Tanzania se convirtió en uno de los principales centros de operaciones del Alto Comisionado de Naciones Unidas para los Refugiados (ACNUR).

En esta ocasión, a diferencia de la década de 1970, las autoridades no recibieron con brazos abiertos a los refugiados e introdujeron políticas más restrictivas. Un primer cambio fundamental fue la determinación de confinar a los recién llegados en campos de refugiados, donde se garantizaba su separación de los habitantes locales. ${ }^{24}$ Posteriormente, el Gobierno comenzó a rechazar la entrada masiva de refugiados ruandeses y adoptó la política de valorar los casos individualmente y ya no de manera colectiva. En respuesta, muchos ruandeses comenzaron a afirmar que eran burundeses para evitar ser repatriados. Sin embargo, el Gobierno también comenzó a insistir en que la situación en Burundi hacía viable la repatriación de los refugiados provenientes de ese país.

\footnotetext{
${ }^{22}$ MaLKKI, LIISA, "Speechless Emissaries: Refugees, Humanitarianism, and Dehistoricization", Cultural Anthropology, vol. 11, núm. 3, 1996, p. 16.

${ }^{23}$ Chaula, Sreeram Sundar, "The Politics of Refugee Hosting in Tanzania: from Open Door to Unsustainability, Insecurity and Receding Receptivity", Journal of Refugee Studies, vol. 16, núm. 2, 2003, p. 147.

${ }^{24}$ Ching'ole, Andrew Stanley, "Refugee and Development in Tanzania: An Exploration of benefits of Refugee Presence on Local Communities A case of North Western Tanzania", Developing Country Studies, vol. 5, núm. 12, 2015, p. 95.
} 
Paralelamente a estas medidas oficiales, se empezó a extender la idea de que la presencia de población refugiada generaba daños al país, pues supuestamente se trataba de personas que no sólo acababan con los recursos naturales, sino amenazaban la seguridad de Tanzania debido a la presencia de milicias, el tráfico de armas y el aumento del crimen.

La preocupación era mayor en las regiones donde la población refugiada alcanzó una proporción muy alta respecto a la población local. ${ }^{25}$ Por todos estos motivos, a principios de la década del 2000, el Gobierno comenzó a insistir en las dificultades que implicaban los refugiados. En 2002, el propio presidente Benjamin Mkapa hizo una serie de declaraciones en las cuales se refería a ellos como una carga que al país le resultaba difícil de mantener. ${ }^{26}$ Este ambiente de puertas cerradas es el que continúa vigente en la actualidad.

\section{Xenofobia y restricción de derechos: sus implicaciones para los migrantes}

En los casos de Sudáfrica y Tanzania se observa con claridad que, a pesar de que en el discurso se asocia con frecuencia la apertura política y la consolidación de los derechos humanos, esta tendencia no siempre ocurre en relación con los migrantes. Aunque no se reconozca de forma oficial, el hecho de que los migrantes estén colocados fuera de la órbita del Estado-nación ocasiona que ciertas cuestiones indispensables para los nacionales de un Estado, no se consideren así para los no nacionales. Peor aún, por esta misma condición, los migrantes se pueden convertir en un blanco perfecto para canalizar las frustraciones de la población frente a los resultados muchas veces decepcionantes de los procesos de apertura. Por ello, no resulta extraño que tanto en Sudáfrica como en Tanzania la liberalización haya ido acompañada por una consolidación de las tendencias xenofóbicas.

En el caso de Sudáfrica, Solomon ubica una de las primeras manifestaciones de xenofobia en el antiguo Bantustán de Gazankulu, en 1990, cuando parte de la población local prendió fuego a 300 chozas de mozambiqueños que habían

\footnotetext{
${ }^{25}$ Fue el caso, por ejemplo, de Kagera, que contaba con aproximadamente 1.5 millones de habitantes, pero entre 1994 y 1996 llegó a albergar a 700000 refugiados. VAN HorwEGHEN, SASKIA, Mobility, territoriality and sovereignty in post-colonial Tanzania, ACNUR, octubre de 2001, p. 17. Disponible en: http://www.unhcr.org/research/working/3b$\mathrm{f101b37/mobility-territoriality-sovereignty-post-colonial-tanzania-saskia-van-hoyweghen.html}$ ${ }^{26}$ IRIN, "ICVA warns against refugee repatriation from Tanzania", 2002. Disponible en: http://www.irinnews.org/ar/ node/199821
} 
llegado a Sudáfrica durante la década de $1980 .{ }^{27}$ Este patrón de ataques contra casas de lámina, pequeños comercios y propiedades de migrantes comenzó a expandirse poco a poco en el territorio sudafricano. Tales reacciones violentas han sido descritas por Crush y Ramachandran como violencia colectiva, la cual implica la organización de un grupo que persigue determinados objetivos económicos, políticos y sociales, y cuyas acciones afectan directamente a los migrantes. ${ }^{28}$

Oficialmente, se han registrado al menos 250 incidentes de violencia colectiva contra refugiados dedicados a la actividad comercial. Estos incluyen el envío de amenazas escritas o verbales, insultos e intimidaciones, violencia en contra de los migrantes y sus empleados, saqueo de sus tiendas, daño físico a sus comercios por medio de incendios premeditados, daño de sus casas o propiedades, desplazamiento forzado de los migrantes de las zonas donde trabajan e incluso el asesinato. ${ }^{29}$

Los ataques xenófobos registrados hasta el momento se concentran en zonas urbanas marginadas, los llamados townships, establecidos por el Gobierno del apartheid para la población no blanca. Ahí existe una competencia por recursos entre los sudafricanos más desfavorecidos y los migrantes. Zondi sostiene que detrás de los ataques xenofóbicos se encuentra la pobreza imperante en estos lugares, la cual se pone de manifiesto con los altos índices de desempleo y abandono escolar por parte de la juventud de piel negra. Aunado a ello, se observa que las células familiares en dichas zonas presentan debilidades. Así, estos sitios se convierten en caldo de cultivo para la violencia contra aquél que es diferente, más aun si posee cosas que los jóvenes consideran deberían tener por ser ciudadanos de la nueva Sudáfrica. ${ }^{30}$

La situación se complica porque el discurso oficial ha creado una cultura de privilegio entre los ciudadanos, ${ }^{31}$ en la cual se imagina a un Estado capaz de proveer todo a sus ciudadanos. Esta cultura se fundamenta en los preceptos de la

\footnotetext{
${ }^{27}$ Solomon, Hussein, Of Myths and Migration. Illegal immigration into South Africa, Pretoria, UnISA, 2003, p. 98.

${ }^{28}$ Crush, Jonathan y Ramachandran, Sujata, "Chapter two. Doing Bussiness with Xenophobia", en Jonathan Crush, y Abel Chikanda (eds.), Mean Streets: migration, xenophobia and informality in South Africa, Ciudad del Cabo, Southern African Migration Programme - the African Centre for Cities - The International Development Research Centre, 2015, pp. 35-42.

${ }^{29}$ Crush, Jonathan y Ramachandran, Sujata, "Chapter two. Doing Bussiness with Xenophobia", en Jonathan Crush, y Abel Chikanda (eds.), Mean Streets: migration, xenophobia and informality in South Africa, Ciudad del Cabo, Southern African Migration Programme - the African Centre for Cities - The International Development Research Centre, 2015, pp. 35-42.

${ }^{30}$ Zondi, SiPHAmandla, "Xenophobic Attacks. Towards and Understanding of Violence against African Immigrants in South Africa", Africa Insight, vol. 38, núm. 2, 2008, p. 29.

${ }^{31}$ ZondI, SiPHAMAndLA, "Xenophobic Attacks. Towards and Understanding of Violence against African Immigrants in South Africa", Africa Insight, vol. 38, núm. 2, 2008, p. 33.
} 
Freedom Charter (1955), donde se establece que todo aquél que vive en territorio sudafricano tiene igualdad de derechos y oportunidades. Sin embargo, un resultado adverso de los principios enarbolados en dicho documento ha sido que parte de la población de piel negra considera que todas sus demandas sociales (agua, luz, vivienda, etcétera) deben ser satisfechas, sin importar si el Gobierno posee o no los recursos necesarios para atender sus peticiones. Ello se refleja en el trato a los migrantes.

La xenofobia general se ve acentuada no sólo desde el discurso político y las reacciones que éste genera de manera extendida entre la población, sino también en el contenido xenófobo de las prácticas institucionales dirigidas hacia los migrantes. ${ }^{32}$ De esta manera, se observa que los esquemas de rechazo pueden perpetuarse aún entre los servidores públicos, como la policía y los oficiales del Department of Home Affairs, encargado del registro de sudafricanos y extranjeros. Aunque no se puede considerar que todos los empleados del gobierno tengan una actitud negativa, algunos estudios han mostrado casos de empleados que demandan sumas de dinero a cambio de sus servicios. Incluso, los migrantes pueden ser víctimas de arrestos arbitrarios y violencia física. ${ }^{33}$

La xenofobia se manifiesta también en el acceso a servicios públicos básicos. De acuerdo con el Afrobarometer 2013 Survey, 45\% de los sudafricanos entrevistados aún mantienen la percepción de que la entrada de extranjeros al país representa una competencia por los trabajos y los beneficios derivados de la ciudadanía sudafricana, tales como el acceso a los servicios de salud. ${ }^{34}$

Algunos documentos legales disponen provisiones que protegen a los migrantes, como la sección 17 de la South African Bill of Rights, donde se establece que todas las personas -incluyendo a quienes no son ciudadanostienen derecho al acceso a los servicios médicos y que nadie puede negar estos servicios. La sección 27 de la Refugees Act (1998) señala que los refugiados que se encuentren en Sudáfrica tienen los mismos derechos a los servicios de salud que sus contrapartes sudafricanas. ${ }^{35}$

\footnotetext{
32 Fourchard, Laurent y Segati, Aurelia, "Introduction of Xenophobia and Citizenship: the everyday politics of exclusion and inclusion in Africa", Africa, vol. 85, núm. 1, 2015, p. 8.

${ }_{33}$ MuRRaY, MARTIN, "Alien Strangers in Our Midst: The Dreaded Foreign Invasion and Fortress South Africa", Canadian Journal of African Studies, vol. 37, núm. 2-3, 2003, pp. 450-451. "Why the Deadly Attacks Against Foreigners In South Africa Come As No Surprise", The Huffington Post, 26 de abril, 2015. [Consulta: 5 de febrero, 2017]. Disponible en: http://www.huffingtonpost.com/2015/04/26/south-africa-xenophobic-attacks_n_7119816.html

${ }^{34}$ La muestra del estudio fue de 2400 participantes a lo largo del territorio sudafricano. MatauRE, Mandla, "Citizens Perception on Migration in South Africa", Afrobarometer Briefing Paper, núm. 112. [Consulta: 5 de febrero, 2017]. Disponible en: http://afrobarometer.org/sites/default/files/publications/Briefing\%20paper/afrobriefno 112_2.pdf

${ }^{35}$ Crush, Jonathan y Tawodzera, Godfrey, "Medical Xenophobia and Zimbabwean Migrant Access to Public Health Services in South Africa", Journal of Ethnic and Migration Studies, vol. 40, núm. 4, 2014, pp. 655-657. [Consulta: 15 de
} 
No obstante, Enwere sostiene que existe confusión entre los refugiados, principalmente en lo relativo al tipo de servicio médico al que deben tener acceso y las limitaciones que presentan. En Sudáfrica se paga una cuota en los hospitales públicos, pero en las clínicas el servicio es totalmente gratuito. Esto ha ocasionado que los refugiados estudiados expresen confusión puesto que en algunas ocasiones han tenido que pagar, no han pagado o se les ha negado el servicio. ${ }^{36}$

Autores como Crush y Tawodzera sostienen que existe un fenómeno de "xenofobia médica", la cual implica una actitud negativa de empleados y profesionales de la salud hacia los migrantes y los refugiados, con base en su identidad como extranjeros. Dicha actitud parece tener varias fuentes, como el grado de tolerancia hacia el otro, la pesada carga laboral, el estrés y las pobres condiciones de trabajo de las enfermeras y médicos que trabajan en hospitales y clínicas públicos, con gran demanda por parte de la población local más pobre. ${ }^{37}$

La xenofobia médica se manifiesta desde el momento en que los migrantes no pueden mostrar sus documentos oficiales vigentes para acreditar su estancia en el país ni pueden presentar una prueba de su residencia por medio de estados bancarios. Una vez que consiguen acceso a los tratamientos médicos, los migrantes pueden correr el riesgo de sufrir abusos verbales. Así sucede en el caso de algunas mujeres embarazadas de Zimbabue, a quienes cuestionan sobre las razones por las que dan a luz en Sudáfrica. Pero, también los migrantes de piel negra pueden ser rechazados por las enfermeras si hablan inglés en vez de una lengua local sudafricana. ${ }^{38}$

En el caso de Tanzania, las muestras de xenofobia no han alcanzado los extremos de violencia física que se han presentado en Sudáfrica. Sin embargo, el rechazo a la presencia de los migrantes se ha vuelto una constante en distintos contextos. Otra tendencia constante ha sido la creciente limitación de los derechos de los refugiados. Ello comenzó a manifestarse con la ya señalada política de confinar a los refugiados en campos separados de las poblaciones locales.

noviembre, 2016]. Disponible en: http://dx.doi.org/10.1080/1369183X.2013.830504

${ }^{36}$ Enwere, Corlivics OnUoha, Human rights and refugee protection in South Africa (1994-2004), Thesis, University of the Witwatersrand, 2006, p. 96.

${ }^{37}$ Crush, Jonathan y Tawodzera, Godfrey, "Medical Xenophobia and Zimbabwean Migrant Access to Public Health Services in South Africa", Journal of Ethnic and Migration Studies, vol. 40, núm. 4, 2014, p. 655. [Consulta: 15 de noviembre, 2016]. Disponible en: http://dx.doi.org/10.1080/1369183X.2013.830504.

${ }^{38}$ Crush, Jonathan y Tawodzera, Godfrey, "Medical Xenophobia and Zimbabwean Migrant Access to Public Health Services in South Africa", Journal of Ethnic and Migration Studies, vol. 40, núm. 4, 2014, pp. 660-664. [Consulta: 15 de noviembre, 2016]. Disponible en: http://dx.doi.org/10.1080/1369183X.2013.830504 
Esta política ha tenido varias consecuencias. Primeramente, quienes abandonen el campo sin permiso pueden perder el reconocimiento oficial de su estatus y, por tanto, su derecho a la protección y la asistencia. En segundo lugar, la formación de grandes campos le dio al fenómeno de la migración un rostro altamente visible. Los refugiados en los campos constituyen un grupo fácil de identificar, sobre el cual (por la misma razón) puede ser relativamente fácil ejercer distintas formas de discriminación.

Como en el caso de Sudáfrica, el ascenso de la xenofobia está relacionado directamente con la competencia por recursos entre migrantes y poblaciones locales. La concentración demográfica y la escasez al interior de los campos provocan que los refugiados busquen recursos para uso cotidiano, como agua y leña, en zonas aledañas a los campos. Con frecuencia, ello genera entre las poblaciones locales una percepción de competencia desleal. Como se mencionó anteriormente, mucha gente afirma que cuestiones como la crisis ecológica o la falta de alimentos derivan de la presencia de los refugiados. ${ }^{39}$

$\mathrm{Al}$ mismo tiempo, algunos problemas generados al interior de los campos, como el incremento de distintos riesgos de seguridad, provocan que múltiples sectores de la opinión pública local rechacen la presencia de una población tan numerosa. En opinión de estos grupos, la presencia de refugiados constituye una carga y provoca que la población local pague, injustamente, las consecuencias de la falta de estabilidad en países que, a diferencia de la propia Tanzania, no han sabido resolver sus propios conflictos. ${ }^{40}$

También se ha extendido la opinión de que los campos de refugiados pueden convertirse en enclaves para despojar a Tanzania de parte de su territorio, a fin de resolver presiones demográficas y de recursos en los países de origen de los migrantes. Algunos consideran que ciertos grupos, como los burundeses,

\footnotetext{
${ }^{39}$ Por ejemplo, con la llegada masiva de refugiados burundeses al campo de Nyarugusu, se delimitó un área de cuatro kilómetros alrededor del campo en donde les estaria permitida la recolección leña. Sin embargo, las necesidades rápidamente sobrepasaron los recursos de esta limitada franja y los refugiados debieron buscar leña en zonas más lejanas. VIGAUD WaLSH, Francisca, "Women and girls failed: The burundian refugee response in Tanzania", Refugees International, 22 de diciembre, 2015. [Consulta: 5 de febrero, 2017]. Disponible en: https://static1.squarespace.com/ static/506c8ea1e4b01d9450dd53f5/t/5678aee07086d7cddecf1bab/1450749707001/20151222+Tanzania.pdf

Esta situación contribuye para que los vecinos de la zona tengan la idea de que son los refugiados quienes acaban con los recursos de la zona, aunque se trate de una visión parcial que no toma en cuenta las múltiples facetas de la deforestación.

${ }^{40}$ Asylum Access Tanzania, No place called home. A report on urban refugees living in Dar es Salaam, Dar es Salaam, Asylum Access Tanzania, p. 7. Disponible en: http://asylumaccess.org/wp-content/uploads/2014/08/No-Place-Called-Home.pdf
} 
son conflictivos por naturaleza, proclives al odio y la venganza, por lo cual su presencia puede desestabilizar al país. ${ }^{41}$

Este tipo de discurso enfatiza lo que Tanzania y la comunidad internacional ofrecen a los refugiados, sin considerar las difíciles condiciones en los campos. Se subraya el acceso que los refugiados tienen a la ayuda internacional y se describe al refugiado como un "mendigo ocioso que vive de la generosidad de otros”. No se consideran, en cambio, las malas condiciones prevalecientes en los campos y el impacto negativo que tienen en la vida de los refugiados.

Durante las primeras etapas de llegada masiva de refugiados a un campo, quienes arriban tienen que ubicarse en alojamientos "temporales", elaborados con troncos y plástico en espacios de 40 metros por $10 .{ }^{42}$ Ahí se pueden concentrar hasta 200 personas que duermen en esteras sobre las cuales difícilmente se pueden colocar mosquiteros. En época de lluvias, el agua penetra con facilidad a estos refugios y los mosquitos que transmiten la malaria proliferan. Estas condiciones derivan en la presencia extendida de enfermedades infecciosas como el cólera o la malaria. ${ }^{43}$ Asimismo, el hacinamiento genera distintos problemas, desde la insuficiencia de recursos básicos, como alimentos y medicinas, hasta los abusos por parte de distintos grupos locales o incluso milicias provenientes de los países vecinos.

De igual manera, es posible observar que algunos grupos resultan especialmente vulnerables, incluyendo a las mujeres, ${ }^{44} \mathrm{y}$ particularmente a las ado-

\footnotetext{
${ }^{41}$ CSFM-IRRI, "I don't know where to go", Burundian Refugees in Tanzania under Pressure to Leave, Dar es Salaam, Centre for the Study of Forced Migration - International Refugee Rights Initiative, 2009, p. 8.

${ }^{42}$ A medida que la situación se "estabiliza", las condiciones de alojamiento pueden mejorar, pero siempre habrá fuertes limitaciones. Si la crisis se prolonga, los migrantes construirán casas con materiales distintos de la madera y el plástico. Sin embargo, el gobierno tanzano ha estipulado que los materiales deben ser perecederos: las paredes serán de adobe sin cocer y los techos de paja. La idea es que cuando la población migrante abandone el lugar, sus viviendas se destruyan sin dejar rastro, para garantizar que los campos mantengan su carácter de espacios temporales. Al mismo tiempo, esta política constituye una forma de violencia simbólica, pues materializa la subordinación y alienación que los refugiados viven en Tanzania. Thomson, Marnie JAne, "Mud, Dust, and Marougé: Precarious Construction in a Congolese Refugee Camp", Architectural Theory Review, vol. 19, núm. 13, 2014, pp. 376-379.

43 "Tanzania: People cope with these tough living conditions because often they haven't known anything else", Médicos sin Fronteras, 9 de diciembre, 2015. [Consulta: 5 de febrero, 2017]. Disponible en: http://www.msf. org/en/article/tanzania-\%E2\%80\%9Cpeople-cope-these-tough-living-conditions-because-often-they-haven\%E2\%80\%99t-known

${ }^{44}$ La violencia puede ocurrir en lugares inseguros al interior de los campos, como las letrinas y los baños, los puntos de distribución de ayuda, o las propias tiendas donde pernoctan los refugiados. En el caso de Nyarugusu, por ejemplo, un estudio de campo reportaba en diciembre de 2015 que las letrinas y las regaderas estaban en puntos lejanos de la zona habitacional, no estaban iluminados durante la noche, solo tenían hojas de plástico a manera de puertas y no contaban con cerraduras. Todo esto ponía en gran riesgo a las usuarias. A su vez, el reparto de ayuda se realiza con frecuencia en puntos alejados y durante la tarde. Dado que las filas se pueden prolongar largo tiempo, en el mismo estudio las mujeres se quejaban de que a menudo se veian obligadas a regresar solas y en la oscuridad, con los consecuentes peligros. Igualmente, debido a la sobrepoblación, las propias tiendas se convertian en puntos
} 
lescentes ${ }^{45}$ así como a los menores, sobre todo si llegan al campo sin la compañía de un adulto. ${ }^{46}$ Por todo ello, los campos de refugiados no ofrecen certeza alguna ni sobre el presente ni sobre el futuro. ${ }^{47}$

Para algunos, la incertidumbre aumenta con las políticas de promoción "indiscriminada” de la repatriación. En varios casos, el Gobierno tanzano ha presionado para cerrar campos de refugiados, argumentando que las condiciones de seguridad en los lugares de origen de estos migrantes han mejorado. Esto sucedió, por ejemplo, con los refugiados congoleses, en el campo de Nyarugusu. En este caso, el Gobierno desechó en última instancia la promoción abierta de la repatriación, y los planes de cerrar este campo se vinieron abajo definitivamente con la llegada masiva de burundeses a partir de 2015. Sin embargo, en los hechos, las autoridades han mantenido una política que prohíbe a los refugiados participar en actividades remuneradas, ${ }^{48}$ lo cual constituye una forma de presión.

La política de promoción del retorno de refugiados también afectaba a los burundeses antes de los sucesos de 2015, los cuales llevaron a un nuevo éxodo hacia Tanzania. ${ }^{49}$ El Gobierno tanzano había ofrecido y, en efecto, extendió la ciudadanía a los refugiados burundeses, pero sólo a quienes habían llegado en la década de 1970. En cambio, para quienes habían migrado a partir de la década de 1990, la opción promovida era la repatriación. El objetivo, que no se

de riesgo. Además del área donde en sentido estricto se exponían a graves riesgos las mujeres que salían del campo para conseguir agua, recolectar leña o para buscar oportunidades de trabajo en las cercanias. VIGAUD WaLSH, FrancISCA, "Women and girls failed: The burundian refugee response in Tanzania", Refugees International, 22 de diciembre, 2015. [Consulta: 5 de febrero, 2017]. Disponible en: https://static1.squarespace.com/static/506c8ea1e4b01d9450dd53f5/t/5678aee07086d7cddecf1bab/1450749707001/20151222+Tanzania.pdf

${ }^{45}$ Women's Refugee Commission, The Path to Hope. Congolese Refugee Adolescent Girls in Nyarugusu Refugee Camp, Tanzania, Nueva York, Women's Refugee Commission, 2012, p. 5. Disponible en: https://www.womensrefugeecommission.org/resources/document/868-the-path-to-hope-congolese-refugee-adolescent-girls-in-nyarugusu-refugee-camp-tanzania

${ }^{46}$ Para los menores, sobre todo los no acompañados, la vida como refugiados supone enormes riesgos y demanda apoyo especializado para garantizar su protección y su seguridad, asi como soporte emocional.

${ }^{47}$ Women's Refugee Commission, The Path to Hope. Congolese Refugee Adolescent Girls in Nyarugusu Refugee Camp, Tanzania, Nueva York, Women's Refugee Commission, 2012, p. 5. Disponible en: https://www.womensrefugeecommission.org/resources/document/868-the-path-to-hope-congolese-refugee-adolescent-girls-in-nyarugusu-refugee-camp-tanzania.

${ }^{48}$ Women's Refugee Commission, The Path to Hope. Congolese Refugee Adolescent Girls in Nyarugusu Refugee Camp, Tanzania, Nueva York, Women's Refugee Commission, 2012, p. 5. Disponible en: https://www.womensrefugeecommission.org/resources/document/868-the-path-to-hope-congolese-refugee-adolescent-girls-in-nyarugusu-refugee-camp-tanzania.

${ }^{49}$ En 2015, el presidente burundés Pierre Nkurunziza manifestó su intención de presentar su candidatura para la reelección. Esta polémica medida precipitó una serie de hechos violentos que se agravaron en 2016 con su reelección. Como resultado, muchos burundeses huyeron del pais. 
logró, era convertir a Tanzania en un país "libre de refugiados" para finales de la década del 2000.50

La caracterización de los refugiados como un riesgo o como entes que saquean los recursos tanzanos perseguirá a estos migrantes incluso cuando se trasladen a las ciudades. Ello traerá como consecuencia la discriminación en distintos ámbitos, agravada por el hecho de que, al desplazarse a las ciudades, los refugiados pueden perder el reconocimiento legal de su estatus por parte del Gobierno. Todo ello los colocará en una posición de mayor indefensión. ${ }^{51}$

Los refugiados en situación irregular, en las ciudades, enfrentan algunas dificultades específicas, relacionadas con la discriminación y con el hecho de no tener documentación adecuada. Un primer problema es el temor constante a ser descubierto, pues en caso de que esto ocurra es probable que el migrante se enfrente de manera directa a actitudes xenófobas, desde el uso de insultos, hasta el uso derogatorio de la propia palabra suajili para los refugiados (mkimbizi).. ${ }^{52}$

Por otro lado, la competencia por recursos seguirá vigente para los migrantes al desplazarse hacia los asentamientos urbanos. Una mujer señalaba las complicaciones que solía tener con sus vecinos, quienes conocían su situación y la discriminaban cuando iba por agua a un pozo comunitario, señalando que no tenía derecho a estar ahí porque era refugiada. El clamor era que los tanzanos debían obtener agua primero.

Igualmente, si se conoce su identidad como migrante irregular, es común que el refugiado deba soportar algunas formas de acoso y en ciertos casos se verá obligado a pagar sobornos para no ser denunciado. Esto puede ocurrir con sus empleadores o incluso con sus vecinos. Además, algunos empleadores pueden reducir o retener los salarios de un trabajador si descubren que es un refugiado sin permiso para residir en la ciudad. Por todo ello, algunos refugiados perciben la vida en Tanzania como más complicada incluso que la vida que llevaban antes de convertirse en refugiados..$^{53}$

\footnotetext{
${ }^{50}$ Asylum Access Tanzania, No place called home. A report on urban refugees living in Dar es Salaam, Dar es Salaam, Asylum Access Tanzania, p. 7. Disponible en: http://asylumaccess.org/wp-content/uploads/2014/08/No-Place-Called-Home.pdf

${ }^{51}$ Oficialmente, un refugiado sólo está autorizado a abandonar los campos por razones médicas, por riesgos temporales de seguridad o con miras al reasentamiento en un tercer pais. Para ello, debe solicitar el permiso de las autoridades correspondientes. Sin embargo, en los hechos muchos optan por partir sin solicitar dicho permiso.

${ }^{52}$ MAnn, GiLlan, "'Finding a Life Among Undocumented Congolese Refugee Children in Tanzania", Children \& Society, vol. 24, 2010, p. 263. En opinión de Mann, el hecho de que parte de la población tanzana se haya apropiado de la palabra refugiado como una forma de degradar al "otro" es un ejemplo claro de discriminación.

${ }^{53}$ Mann relata, por ejemplo, cómo un menor congolés, que en su país había enfrentado dificultades considerables, incluyendo el haber sido secuestrado para combatir en una milicia local, afirmaba que, a pesar de todo, la vida en Tanzania era mucho más dura a causa de las continuas humillaciones y problemas que debía enfrentar. MANN, GILLAN,
} 


\section{Acción de los migrantes: estrategias para el fortalecimiento de la agencia}

Como se observa, tanto en Sudáfrica como en Tanzania, los migrantes se han visto confrontados a una tendencia creciente a la limitación de sus derechos por medio de acciones xenófobas de distinta envergadura. En ambos casos, amplios sectores de la opinión pública ven en estos migrantes una amenaza, ya sea porque consideran que compiten por los recursos o porque los asocian con distintos riesgos para la seguridad. Por su parte, los gobiernos han tomado distintas medidas diseñadas para limitar, desde distintos puntos de vista, los derechos de los migrantes.

Ante las presiones contra sus derechos, los migrantes buscan explotar al máximo sus oportunidades, aun cuando éstas sean limitadas. Lejos de aceptar en forma pasiva la situación, han desarrollado una serie de estrategias distintas para hacerle frente. Ello demuestra que su capacidad de agencia está presente incluso en un contexto de grandes dificultades. Como señalan West y Wambugu, los migrantes "toman lo que poseen y construyen un sistema para obtener lo que necesitan". ${ }^{54}$ Sin embargo, con frecuencia la estructura de oportunidades constituirá una barrera y sus acciones no tendrán el resultado deseado, de manera que no desembocan en un empoderamiento definitivo.

Ante las manifestaciones xenófobas que los migrantes en Sudáfrica deben enfrentar de manera cotidiana, han buscado diversas vías para empoderarse. La necesidad de transformar la realidad que viven en el país receptor los lleva a organizarse en torno a sus capacidades humanas, sociales y colectivas. A continuación, se analizan cuatro vertientes de la acción: las formas en que se han desarrollado en el comercio informal; la búsqueda de apoyo por parte de las organizaciones no gubernamentales (onG); las manifestaciones de los migrantes en la esfera pública, y la construcción de comunidades en ciertas partes de Sudáfrica como un medio de preservación de su identidad.

\footnotetext{
"Beyond war: 'suffering' among displaced Congolese children in Dar es Salaam", Development in Practice, vol. 22, núm. 4, 2012, p. 450.

${ }^{54}$ En su estudio de principios de la década de 2000, las autoras trabajan especificamente el tema de las redes de información entre los refugiados, pero este es un principio básico en relación con la capacidad de agencia de una manera más general. WeSt, AMY y WAMBUGU, W. LYDIA, Left to their own Devices. The Impact of Informal Information and Communication Networks on Security in the Tanzanian Refugee Camps, Londres, Article 19, 2003, p. 2.
} 


\section{Estrategias en el comercio informal}

Una parte de los migrantes africanos que llegan al territorio sudafricano (somalíes, etíopes, mozambiqueños, entre otros) se dedica al comercio informal en ciertos espacios geográficos como los townships, donde han establecido pequeñas tiendas denominadas spaza shops construidas con antiguos contenedores. Algunos se han incorporado en pequeños locales de las ciudades y otros más colocan mesas improvisadas en las calles. Incluso, es posible encontrar comerciantes ambulantes que recorren las calles de asentamientos informales como Ivory Park, (al norte de Johannesburgo), ofreciendo sus mercancías (frutas, verduras y carne) en carros de supermercado. ${ }^{55}$

Estos comerciantes adoptan ciertas estrategias de mercadotecnia con el fin de garantizar su supervivencia. Crush señala que una estrategia es brindar mejores precios que sus competidores, vender productos a consignación y poner en oferta determinados productos cuando los trabajadores sudafricanos reciben sus pagos. ${ }^{56}$ Además, algunos de los comerciantes obtienen mercancías a bajo precio desde su país de origen, mediante redes informales. Así, pueden transportar pescado y verduras frescas a bajo precio desde Mozambique, o bien, escobas hechas a mano desde Zimbabue. ${ }^{57}$

Otra estrategia utilizada por estos comerciantes consiste en aprender las lenguas africanas locales para poder comunicarse mejor con sus clientes y proveedores. Gumbo sostiene que, por ejemplo, si los comerciantes en Soweto hablan zulú y setsuana, pueden comunicarse más fácilmente con sus clientes, particularmente con los niños, quienes son enviados por sus padres para comprar y no pueden expresarse propiamente en inglés. ${ }^{58}$

\footnotetext{
${ }^{55}$ Charman, Andrew y Peterson, Leif, "A Transnational Space of Business: The Informal Economy of Ivory Park, Johannesburg", en Jonathan Crush, y Abel Chikanda (eds.), Mean Streets: migration, xenophobia and informality in South Africa, Ciudad del Cabo, Southern African Migration Programme - the African Centre for Cities - The International Development Research Centre, 2015.

${ }^{56}$ CRUSH, Jonathan, et al., "Migrant Entrepreneur and informality in South Africa", en Jonathan Crush y Abel Chikanda (eds.), Mean Streets: migration, xenophobia and informality in South Africa, Ciudad del Cabo, Southern African Migration Programme - African Centre for Cities - The International Development Research Centre, 2015, pp. 6-13.

${ }^{57}$ Charman, Andrew y Peterson, LefF, "A Transnational Space of Business: The Informal Economy of Ivory Park, Johannesburg", en Jonathan Crush, y Abel Chikanda (eds.), Mean Streets: migration, xenophobia and informality in South Africa, Ciudad del Cabo, Southern African Migration Programme - the African Centre for Cities - The International Development Research Centre, 2015, p. 89.

${ }^{58}$ Gumbo, Trynos, "Resilience and Innovation: Migrant Spaza Shops Entrepreneurs in Soweto, Johannesburg", en Jonathan Crush y Abel Chikanda (eds.), Mean Streets: migration, xenophobia and informality in South Africa, Ciudad del Cabo, Southern African Migration Programme - African Centre for Cities - The International Development Research Centre, 2015, p. 110.
} 
Otra forma en que los migrantes buscan ampliar su capacidad de acción es recurriendo a grupos de ahorro, dado que las instituciones financieras locales no les otorgan ningún tipo de préstamo, por no ser ciudadanos o residentes permanentes. La presencia de este tipo de alternativas financieras es común en una parte de Johannesburgo conocida como Jeppe. ${ }^{59}$ En cambio, en los townships como Soweto, los migrantes dedicados a los spaza shops no cuentan con este tipo de grupos, pero ahorran individualmente, a fin de invertir en sus negocios y enviar dinero a su país de origen. ${ }^{60}$

Los migrantes recurren también a otros sistemas financieros alternativos para realizar envíos de dinero. Entre ellos, destacan el Tsonga Underground Money Transfer System utilizado por los mozambiqueños para mandar dinero a sus familiares con la ayuda de un taxista encargado de transportarlo hasta su destino final. ${ }^{61}$ Otro sistema es el Hawala, el cual implica una transferencia mediante una llamada telefónica a un contacto específico en el país donde se recibirá el dinero. Otro punto de apoyo es el establecimiento de vínculos entre migrantes. En el caso de las spaza shops de Soweto, se observa que dichos lazos sirven a los nuevos comerciantes para obtener un entrenamiento informal durante un año o más por parte de los comerciantes ya establecidos. Son entrenados como aprendices en las spaza shops existentes, donde reciben un pago. En algunas ocasiones, ese dinero sirve para iniciar sus propios negocios. ${ }^{62}$

\section{Estableciendo vínculos: migrantes y organizaciones no gubernamentales}

Una parte importante de los migrantes africanos se concentra en las zonas rurales. Generalmente, los migrantes reciben bajos salarios y sus condiciones de

\footnotetext{
${ }^{59}$ ZACK, TANYA, "Making an Area Hot: Interrumpting Trade in an Ethnic Enclave in Johannesburg's Inner City", en Jonathan Crush y Abel Chikanda (eds.), Mean Streets: migration, xenophobia and informality in South Africa, Ciudad del Cabo, Southern African Migration Programme - African Centre for Cities - The International Development Research Centre, 2015, p. 69.

${ }^{60}$ Gumbo, TrYnos, "Resilience and Innovation: Migrant Spaza Shops Entrepreneurs in Soweto, Johannesburg", en Jonathan Crush y Abel Chikanda (eds.), Mean Streets: migration, xenophobia and informality in South Africa, Ciudad del Cabo, Southern African Migration Programme - African Centre for Cities - The International Development Research Centre, 2015, p. 105.

61 "Exploring Tsonga Underground Money Transfer System-SA to Moz", Vivmag. [Consulta: 10 de octubre, 2016]. Disponible en: http://www.vivmag.co.za/archives/10297

${ }^{62}$ Gumbo, Trynos, "Resilience and Innovation: Migrant Spaza Shops Entrepreneurs in Soweto, Johannesburg", en Jonathan Crush y Abel Chikanda (eds.), Mean Streets: migration, xenophobia and informality in South Africa, Ciudad del Cabo, Southern African Migration Programme - African Centre for Cities - The International Development Research Centre, 2015, p. 108.
} 
trabajo son malas. En este contexto, las oNG sudafricanas que operan cerca de las fronteras de Sudáfrica y Zimbabue brindan apoyo a los trabajadores migratorios, especialmente, a los de las granjas, para que puedan tener acceso a tratamientos contra el sida, mejores condiciones de trabajo y salarios más altos. ${ }^{63}$

En las grandes ciudades, las oNG también apoyan a los migrantes en la medida de lo posible. Después de los ataques xenófobos del 2008 en Ciudad del Cabo, algunas organizaciones emprendieron acciones como la colecta de cobijas y comida para apoyar a los migrantes que se alojaban en los albergues. Incluso, recurrieron a una alianza con organismos como Aids Law Project, para demandar al Gobierno de la provincia de Western Cape que mejorara las condiciones de los albergues. ${ }^{64}$

Sin lugar a dudas, los migrantes que sufrieron los ataques del 2008 se sintieron apoyados por las oNG, pero quizás lo más importante es que fueron capaces de mostrar su inconformidad públicamente a través de organizaciones como Africa Unite, Afri-South, The Somali Association of South Africa (Western Cape), the Somali Traders Association y The African Disabled Peoples Organisation. Las asociaciones de somalíes pidieron de manera particular que se mejoraran las condiciones de los albergues, e inclusive organizaron huelgas de hambre para presionar a las autoridades locales. ${ }^{65}$

\section{Manifestaciones públicas}

Los migrantes africanos han planteado algunas inconformidades a través de marchas aisladas que ocurren en ciertas coyunturas. En el caso específico de los refugiados congoleños, se observa que han manifestado su inconformidad ante la situación de los refugiados, la xenofobia y el mal funcionamiento del Department of Homme Affairs. ${ }^{66}$ Sin embargo, es difícil lograr el consenso entre los

\footnotetext{
${ }^{63}$ HLATSHWAYO, MondL, "Xenophobia, Resilience, and Resistance of Immigrants Workers in South Africa: Collective and Individual Responses", en Aziz Choudry y Mondi Hlatswayo (eds.), Just Work? Migrant Workers's Struggles Today, Londres, Pluto Press, 2016, p. 29.

${ }^{64}$ Jara, Mazibuko y Peberdy, Sally, "Progressive Humanitarian and Social Mobilisation in a Neo-Apartheid Cape Town: A Report on Civil Society and the May 2008 Xenophobic violence. Research Report", The Atlantic Philanthopies, pp. 35-37. [Consulta: 7 de octubre, 2016]. Disponible en: http://www.atlanticphilanthropies.org/app/uploads/2010/07/2_ Cape_town_c.pdf

${ }^{65}$ Jara, Mazibuko y Peberdy, Sally, "Progressive Humanitarian and Social Mobilisation in a Neo-Apartheid Cape Town: A Report on Civil Society and the May 2008 Xenophobic violence. Research Report", The Atlantic Philanthopies, p. 40. [Consulta: 7 de octubre, 2016]. Disponible en: http://www.atlanticphilanthropies.org/app/uploads/2010/07/2_ Cape_town_c.pdf

${ }^{66}$ Amisl, Baruti y Balard, Richard, "In the Absence of Citizenship: Congolese refugee struggle and organization in South Africa. A case of study for ukZn project entitled: Globalisation, Marginalisation and New Social Movements in
} 
refugiados, pues existen diversas posiciones, desde la manifestación como único medio de ser vistos y escuchados en público, hasta el silencio por miedo a ser deportados. ${ }^{67}$

Además de los refugiados, otros grupos también han recurrido a las manifestaciones como medio de empoderamiento. Un ejemplo es el de un grupo de migrantes dedicados a las actividades comerciales informales. En 2014, ellos pudieron lograr un avance significativo a pesar de sus diferencias cuando los comerciantes ambulantes, tanto sudafricanos como migrantes, enfrentaron órdenes de desalojo del centro de la ciudad de Johannesburgo. En respuesta, los comerciantes se unieron, sin importar su nacionalidad, con el South African Informal Traders Forum (SAITF) para pedir justicia a la máxima corte sudafricana, la Constitutional Court. La corte falló a favor de los comerciantes, quienes pudieron volver a sus actividades económicas. Esta victoria jurídica es una pequeña muestra de que los intentos de agencia pueden resultar en algo positivo, y benéfico tanto para ellos mismos como para los nacionales del país receptor. ${ }^{68}$

\section{Concentración geográfica y preservación de la identidad}

De acuerdo con Epstein y Gang, los migrantes internacionales pueden formar concentraciones en partes específicas de una ciudad, pueblo o región del país receptor. Existen diversas razones que llevan a la conformación de este tipo de comunidades. Entre ellas, destaca la existencia de migrantes que han llegado previamente a la zona y pueden proporcionar hospedaje, trabajo o asistencia financiera, o que simplemente ayudan a reducir el estrés de moverse a un país extraño. ${ }^{69}$

post-Apartheid South Africa", Durban, University of Kwazulu-Natal, 2005, pp. 3-6. [Consulta: 8 de octubre, 2016]. Disponible en: http://ccs.ukzn.ac.za/files/Amisi\%20Ballard\%20Refugees\%20Research\%20Report.pdf

${ }^{67}$ Incluso, la pertenencia étnica alinea a los refugiados en determinados grupos que se unen por diferentes motivos, como la organización de funerales. Se crea así una red de apoyo entre migrantes capaz de colectar fondos. Sin embargo, estas redes van más allá del mundo material; buscan la preservación de sus lenguas, proverbios y tradiciones entre sus miembros. Véase Amisı, Baruti y Ballard, Richard, "In the Absence of Citizenship: Congolese refugee struggle and organization in South Africa. A case of study for UKZN project entitled: Globalisation, Marginalisation and New Social Movements in post-Apartheid South Africa", Durban, University of Kwazulu-Natal, 2005, pp. 8-11. [Consulta: 8 de octubre, 2016]. Disponible en: http://ccs.ukzn.ac.za/files/Amisi\%20Ballard\%20Refugees\%20Research\%20 Report.pdf

${ }^{68}$ Hlatshwayo, Mondu, "Xenophobia, Resilience, and Resistance of Immigrants Workers in South Africa: Collective and Individual Responses", en Aziz Choudry y Mondi Hlatswayo (eds.), Just Work? Migrant Workers's Struggles Today, Londres, Pluto Press, 2016, p. 32.

${ }^{69}$ Epstein, Gil y Gang, Iran, "Migration and Culture", iza dp, núm. 5123, 2010, p. 3. [Consulta: 9 de octubre, 2016]. Disponible en: http://ftp.iza.org/dp5123.pdf 
Este es el caso de los migrantes somalíes que viven en las principales ciudades y algunos pueblos de Sudáfrica. En las grandes ciudades han formado concentraciones como las referidas por Epstein y Gang. En Johannesburgo, por ejemplo, se han asentado en el llamado Little Mogadishu (oficialmente conocida como Mayfair), donde han establecido restaurantes y tiendas que ofrecen transferencias monetarias, comida, viajes y ropa. Little Mogadishu se ha vuelto también área residencial establecida sólo para somalíes.

$\mathrm{Al}$ combinarse el campo laboral y residencial, se hace posible que la comunidad comparta algunos elementos culturales comunes. Por ejemplo, el Towakal 2 Supermaket ofrece a sus clientes productos que consumían en Somalia, como arroz asiático y jugos de Arabia Saudita. ${ }^{70}$ La posibilidad de comer ciertos alimentos similares a los que consumían en Somalia les permite a los somalíes vivir en un ambiente cultural que evoca el de su país de origen. ${ }^{71} \mathrm{La}$ religión es otro elemento importante para estos somalíes, ya que cuentan con una mezquita cercana a sus negocios. Esto no sucede con los somalíes que se han establecido fuera de las ciudades. ${ }^{72}$

Sin embargo, el establecimiento de migrantes en determinadas comunidades a veces tiene resultados adversos para el país receptor. Se sabe, por ejemplo, que algunos nigerianos han tomado control de zonas como Sunnyside, en Pretoria, o Hillbrow, en Johannesburgo, donde realizan actividades ilícitas como tráfico de drogas y estafas. ${ }^{73}$

Como en el caso de Sudáfrica, en Tanzania los estereotipos han permeado en gran medida la concepción que existe sobre los migrantes. De manera central, el flujo hacia territorio tanzano de enormes grupos de refugiados que se mantienen separados de la población y confinados en campos contribuye a que estos migrantes sean altamente visibles y favorece la percepción de que su única actividad es esperar la ayuda internacional. Esto genera una tendencia a creer que la capacidad de agencia debe provenir del exterior.

La inclinación a pensar en los refugiados como entes sin agencia se refleja en el lenguaje mismo. Considerar a los refugiados migrantes forzados, a

\footnotetext{
70 Sulaiman, PhILIP, "From Mogadishu to Mayfair: Somali diaspora finds home in Johannesburg", Brand South Africa, 2016. [Consulta: 9 de octubre, 2016]. Disponible en http://www.mediaclubsouthafrica.com/africa/4459-from-mogadishu-to-mayfair-somali-diaspora-finds-home-in-johannesburg

${ }^{71}$ Epstein, Gll y Gang, IRAn, "Migration and Culture", iza dp, núm. 5123, 2010, p. 3. [Consulta: 9 de octubre, 2016]. Disponible en: http://ftp.iza.org/dp5123.pdf

72 Sadouni, Samadia, "The stratified diasporas of Somalians", Mail \& Guardian, 13 de febrero, 2015. [Consulta: 9 de octubre, 2016]. Disponible en: http://mg.co.za/article/2015-02-13-the-stratified-diasporas-of-somalians/ 73 "R60m drug bust in Pretoria", Sowetan Live, 13 de septiembre, 2012. [Consulta: 9 de octubre, 2016]. Disponible en: http://www.sowetanlive.co.za/news/2012/09/13/r60m-drug-bust-in-pretoria?filter=all_comments
} 
diferencia de los llamados migrantes económicos -que serían "voluntarios"oculta una realidad fundamental: para estas personas, el hecho de haber buscado refugio fuera de su país para evitar una situación de riesgo constituye por sí mismo una importante muestra de agencia y capacidad de decisión. Los refugiados no son simplemente arrastrados por la marea de la violencia. En una situación de inestabilidad, no todas las personas optan por migrar; hacerlo constituye una decisión estratégica. Las historias de vida de los refugiados están llenas de elementos que revelan una fuerte capacidad de acción bajo condiciones extremas. Desde el momento en que deciden abandonar su lugar de residencia, enfrentarán una serie de riesgos. ${ }^{74}$ La capacidad de decisión se vuelve entonces fundamental en todo momento, pues no ejercerla en forma consciente pondría en riesgo sus propias vidas.

\section{La agencia bajo control institucional: los campos de refugiados}

La capacidad de decisión no se extingue con la llegada a un campo de refugiados. Como se revisó en las páginas anteriores, estos son lugares donde los migrantes confrontan situaciones que constantemente ponen en riesgo sus derechos humanos. Por ello, deberán desplegar una serie de estrategias para enfrentar las presiones cotidianas.

Podemos tomar como ejemplo una historia de vida. Un hombre entrevistado en 2009, en el campo de Mtabila, relataba que, ya en el campo de refugiados, grupos rebeldes le exigían contribuir con su movimiento. El hombre rechazó las presiones y se negó a contribuir, por lo cual fue señalado como traidor. Él buscó ayuda del Comité Internacional de la Cruz Roja y el culpable fue encarcelado primero y repatriado posteriormente, pero el refugiado fue amenazado con que, en caso de regresar a su país en cualquier momento futuro, sería asesinado. ${ }^{75}$

Este caso ilustra que incluso en situaciones extremas queda abierto un pequeño espacio para la agencia y la capacidad de decisión, aunque sea de manera limitada. En el ejemplo, el refugiado opta por actuar en contra de las presiones y mantiene su decisión de manera consciente, aun teniendo poco espacio de maniobra. Aunque la decisión del refugiado requirió apoyo externo (el de la Cruz Roja), ésta fue tomada de manera personal por el refugiado, quien

\footnotetext{
${ }^{74}$ Los riesgos incluyen la posibilidad de ataques sexuales, los ataques por parte de milicias o miembros de los ejércitos regulares, extorsiones, falta de agua y alimentos, entre muchos otros.

${ }^{75}$ CSFM-IRRI, "I don't know where to go", Burundian Refugees in Tanzania under Pressure to Leave, Dar es Salaam, Centre for the Study of Forced Migration-International Refugee Rights Initiative, 2009, p. 6.
} 
elige un curso específico de acción sabiendo que ello limitará sus posibilidades en el futuro.

Este ejemplo de decisión estratégica es un caso extremo, pero no aislado. Hay otras muchas estrategias que los refugiados desarrollan para maximizar su capacidad de acción. Una de las más importantes, al igual que en Sudáfrica, es la construcción de redes sociales y sistemas de apoyo. Se trata de una forma de capital social, que "encuentra su valor en la manera como las masas se organizan para convertirse en una red". ${ }^{76}$ Para Willems, estas redes son el canal por excelencia a través del cual los refugiados reconstruyen sus vidas en el nuevo ambiente al que llegan. ${ }^{77}$ Su creación se facilita, en parte, por las condiciones de vida en los campos, sobre todo por la cercanía física obligada entre sus habitantes.

Con frecuencia, estos sistemas no se encuentran plenamente desarrollados o son poco utilizados. Pero, en todo caso, constituyen un apoyo para proteger y facilitar la vida de los refugiados. A los jóvenes, especialmente en etapas críticas como la adolescencia, las redes pueden ayudarles a enfrentar sus problemas específicos y resolver necesidades concretas de su edad ${ }^{78}$ (relacionadas por ejemplo con el ejercicio de la sexualidad, la toma de decisiones y la formación de la identidad personal). A los refugiados, en general, las redes pueden ofrecerles elementos de protección en las difíciles circunstancias de los campos. ${ }^{79}$ Estos sistemas también se utilizan para establecer canales de comunicación. ${ }^{80}$ Otra forma en que los refugiados se benefician de las redes es con acciones para mejorar sus condiciones materiales de vida. ${ }^{81}$

\footnotetext{
${ }^{76}$ West, Amy y Wambugu, W. LYdia, Left to their own Devices. The Impact of Informal Information and Communication Networks on Security in the Tanzanian Refugee Camps, Londres, Article 19, 2003.

77 Willems, Roos, "Coping with Displacement: Social Networking among Urban Refugees in an East African Context", en Itaru Ohta y Gebre Yntiso (eds.), Displacement Risks in Africa: Refugees, Resettlers and their Host Populations, Australia, Trans Pacific Press, 2005, p. 53.

${ }^{78}$ Women's Refugee Commission, The Path to Hope. Congolese Refugee Adolescent Girls in Nyarugusu Refugee Camp, Tanzania, Nueva York, Women's Refugee Commission, 2012, p. 6. Disponible en: https://www.womensrefugeecommission.org/resources/document/868-the-path-to-hope-congolese-refugee-adolescent-girls-in-nyarugusu-refugee-camp-tanzania

${ }^{79}$ Por ejemplo, formando grupos para ir a buscar agua y leña, de manera que estas tareas no las realicen mujeres solas, que pueden ser victimas de ataques. VIGAUD WALSH, FrancISCA, "Women and girls failed: The burundian refugee response in Tanzania", Refugees International, 22 de diciembre, 2015. [Consulta: 5 de febrero, 2017]. Disponible en: https://static1.squarespace.com/static/506c8ea1e4b01d9450dd53f5/t/5678aee07086d7cddecf1bab/1450749707001/20151222+Tanzania.pdf

${ }^{80}$ En un campo de refugiados, la información es fundamental: por una parte, es un recurso crucial para la seguridad; por otro lado, puede utilizarse como una herramienta de poder. Sin embargo, con frecuencia existe entre los refugiados la percepción de que los canales oficiales de información no son confiables. West, AmY y WAMBUGU, W. LYDIA, Left to their own Devices. The Impact of Informal Information and Communication Networks on Security in the Tanzanian Refugee Camps, Londres, Article 19, 2003, pp. 2 y 24.

${ }^{81}$ Por ejemplo, el ya citado uso obligatorio de materiales perecederos en la construcción de sus casas provoca que los refugiados enfrenten un continuo proceso de desgaste de las mismas, a lo cual deben responder con la constan-
} 
En este sentido, una estrategia a la cual recurren muchos refugiados es la venta de productos que reciben a través de los canales de ayuda. De esta forma pueden obtener desde alimentos más acordes con sus gustos, hasta productos necesarios que no se distribuyen -o se distribuyen de manera insuficiente- a través de la ayuda internacional, cuyas opciones son bastante limitadas. El uso comercial de esta ayuda se ha interpretado en ocasiones como una forma de abuso por parte de los refugiados. Sin embargo, desde otra perspectiva se le puede considerar una acción que ellos utilizan para tratar de reasumir, al menos de manera parcial, el control sobre algunos aspectos de su vida.

\section{La agencia fuera del radar oficial: refugiados urbanos indocumentados}

Otra estrategia a la que los refugiados en Tanzania pueden recurrir es mucho más radical por sus consecuencias. Se trata de abandonar los campos para trasladarse a otros lugares, principalmente a centros urbanos como Kigoma, Mwanza o Dar es-Salam. Las motivaciones para que un refugiado abandone un campo pueden ser muchas, desde evitar la pobreza y las malas condiciones de vida ${ }^{82}$ hasta tratar de continuar con la educación de los jóvenes, o buscar oportunidades de trabajo y de realización personal en general. Otra razón es el intento de evitar una situación probable de repatriación. También es común que los refugiados opten por abandonar un campo debido a cuestiones de seguridad, ${ }^{83} \mathrm{o}$ bien, por buscar la reunificación familiar.

La decisión de un refugiado de trasladarse de forma permanente a una zona fuera de la vigilancia oficial es un ejemplo particularmente claro de la

\footnotetext{
te reconstrucción de lo que el clima va destruyendo. En ocasiones, es posible que los vecinos presten su ayuda para facilitar el proceso de reconstrucción. Thomson, Marnie Jane, "Mud, Dust, and Marougé: Precarious Construction in a Congolese Refugee Camp", Architectural Theory Review, vol. 19, núm. 13, 2014, pp. 376-379.

${ }^{82}$ Willems reporta que, al ser cuestionados sobre sus razones para abandonar los campos de refugiados en donde recibían ayuda humanitaria, más de la mitad de los entrevistados mencionó que se relacionaban con la percepción de la vida en los campos como "miserable", por falta de alimentos, prevalencia de enfermedades y condiciones de vida intolerables. Esto, desde luego, va directamente contra la concepción del refugiado como alguien pasivo que está esperando la ayuda internacional para aprovecharse de ella. WiLLems, Roos, "Coping with Displacement: Social Networking among Urban Refugees in an East African Context", en Itaru Ohta y Gebre Yntiso (eds.), Displacement Risks in Africa: Refugees, Resettlers and their Host Populations, Australia, Trans Pacific Press, 2005, p. 57.

${ }^{83} \mathrm{En}$ el caso de quienes abandonan los campos por razones de seguridad, sus percepciones propias no necesariamente coinciden con las percepciones oficiales. Es común que las peticiones de reubicación en áreas urbanas sean rechazadas. Para muchos migrantes, el rechazo se presenta porque las autoridades no toman con seriedad su situación. En tal caso, es muy probable que el refugiado en cuestión decida no seguir los lineamientos oficiales. WiLlems, Roos, "Coping with Displacement: Social Networking among Urban Refugees in an East African Context", en Itaru Ohta y Gebre Yntiso (eds.), Displacement Risks in Africa: Refugees, Resettlers and their Host Populations, Australia, Trans Pacific Press, 2005, p. 58.
} 
tensión constante entre la agencia del migrante y la capacidad de éste para que sus acciones tengan las consecuencias deseadas. Al abandonar el campo en que están registrados, se colocan fuera de la órbita de "protección" y pierden la posibilidad de obtener documentos oficiales de identificación. En consecuencia, su situación será la de migrantes indocumentados, lo cual implica la pérdida de cualquier posibilidad de protección legal y ayuda humanitaria. ${ }^{84}$

Ante tales circunstancias, pareciera que la mejor opción para los refugiados es tratar de obtener un permiso para residir en la ciudad. Sin embargo, esta es la opción menos utilizada. Muchos deciden no solicitar oficialmente el permiso, a fin de no llamar la atención de las autoridades. Para estas personas, la opción más atractiva es adoptar un bajo perfil y mantenerse tan alejados como sea posible del escrutinio público.

En varios sentidos, los refugiados indocumentados en las ciudades se vuelven "invisibles" para el sistema. Son difíciles de ubicar y con frecuencia se desconoce qué pasa finalmente con ellos. Esto constituye un reto para las instituciones. Para el Gobierno, se convierten en una población en cierto sentido subversiva, pues al salir de los campos han actuado directamente contra las disposiciones gubernamentales. Asimismo, gran parte de su estrategia es no ser detectados por las autoridades, lo cual de nueva cuenta, resulta subversivo.

Ante la pérdida efectiva de su reconocimiento oficial como refugiados -acompañada por la pérdida de derechos que ello conlleva-, quienes se trasladan de los campos a las ciudades deben buscar formas creativas de resolver sus necesidades, sin ningún tipo de apoyo oficial ni de asistencia humanitaria. Ello constituye un verdadero reto ${ }^{85}$ Las necesidades de los refugiados urbanos varían de un caso a otro, pero incluyen, desde buscar los medios necesarios para la subsistencia, hasta asegurar que pueden continuar con su vida en el nuevo medio que han elegido.

Para quienes llegan a las ciudades en estas condiciones, es fundamental mantenerse fuera de la mira de las autoridades, para tratar de construir una nueva vida. Sin embargo, no se trata de una misión sencilla. De manera cons-

\footnotetext{
${ }^{84}$ La oficina del ACNUR en Dar es Salaam no ofrece servicios de protección o asistencia para los refugiados que hayan abandonado por cuenta propia los campos y se hayan instalado en la ciudad sin permiso. Excepcionalmente, y de manera extraoficial, puede confirmar el estatus de refugiado o de solicitante de asilo a refugiados urbanos que hayan sido arrestados, a fin de evitar su deportación, pero esto ocurre sólo ocasionalmente. Véase Asylum Access TanzanIA, No place called home. A report on urban refugees living in Dar es Salaam, Dar es Salaam, Asylum Access Tanzania, p. 7. Disponible en: http://asylumaccess.org/wp-content/uploads/2014/08/No-Place-Called-Home.pdf ${ }^{85}$ Willems, Roos, "Coping with Displacement: Social Networking among Urban Refugees in an East African Context", en Itaru Ohta y Gebre Yntiso (eds.), Displacement Risks in Africa: Refugees, Resettlers and their Host Populations, Australia, Trans Pacific Press, 2005, p. 58
} 
tante, los refugiados urbanos enfrentan el temor de ir a la cárcel o ser deportados. En un estudio realizado por 0'Loghlen, muchos de los participantes reportaron numerosos incidentes con la policía. En muchos casos, habían sido arrestados y sólo fueron liberados después de pagar sobornos importantes. Poco tiempo después de un episodio de este tipo, la situación podía repetirse. ${ }^{86}$

Tales condiciones constituyen una seria limitante para la acción de estas personas. No implican solamente pérdidas económicas ocasionales (en forma los sobornos que deben pagar), sino que constituyen uno de los grandes obstáculos para el empoderamiento de los refugiados. El riesgo de ser detectados por las autoridades y la necesidad de evitarlo repercuten de manera negativa en las relaciones con el entorno. Si la situación irregular del refugiado queda expuesta, se pueden suscitar numerosos conflictos con empleadores, compañeros de trabajo, caseros, vecinos, entre otros, provocando, desde discriminación, hasta retención de salarios. ${ }^{87}$

En vista de las condiciones adversas que deben enfrentar de manera continua, para los refugiados en situación irregular se vuelve más importante la capacidad de negociar espacios seguros, más allá de los canales oficiales. De nueva cuenta, como en el caso de los refugiados que permanecen en los campos, las decisiones de quienes se asientan de manera irregular en las áreas urbanas y las redes que puedan establecer son recursos centrales, pues, como señala Willems, estas personas "necesariamente dependen de sí mismas y de los miembros de sus redes sociales". ${ }^{88}$

Una estrategia que el refugiado urbano puede intentar es ocultar su identidad en el sitio de trabajo o en el lugar donde vive. Un modo de hacerlo es limitando sus interacciones sociales, a fin de reducir las posibilidades de quedar expuestos. Al respecto, un refugiado señalaba que trataba de no integrarse con los otros para no verse obligado a hablar en suajili, porque su limitado manejo del idioma podía provocar que lo identificaran como refugiado.

Para hacer frente a las sospechas que pueden derivar del manejo del suajili, algunos refugiados recurren a la estrategia de adoptar una identidad étnica específica que pueda justificar su acento. De manera deliberada, algunos re-

\footnotetext{
${ }^{86}$ De los participantes en el estudio, $45 \%$ reportó haber sido detenido una vez, mientras que $4 \%$ señaló que había sufrido hasta cuatro detenciones. Los sobornos reportados oscilaban entre 50000 y 150000 chelines tanzanos.

${ }^{87}$ Muchos refugiados asentados irregularmente en Dar es Salaam reportaron haber sido detenidos después de que vecinos, empleadores o acreedores los reportaran ante las autoridades por su situación irregular.

${ }^{88}$ WILLEMS, Roos, "Coping with Displacement: Social Networking among Urban Refugees in an East African Context", en Itaru Ohta y Gebre Yntiso (eds.), Displacement Risks in Africa: Refugees, Resettlers and their Host Populations, Australia, Trans Pacific Press, 2005, p. 55.
} 
fugiados en situación irregular prefieren centrar sus interacciones sociales en ambientes que consideran más seguros, como las iglesias.

Más allá del tema de preservar su identidad, otra necesidad de los refugiados indocumentados en las áreas urbanas es la de conseguirse la vida. ${ }^{89}$ Limitados en su capacidad de elección a causa de la falta de documentos, la mayoría opta por trabajos informales o el autoempleo en negocios que requieren poca inversión. El rango de ocupaciones que realizan estas personas es amplio, pues incluye las labores como empleados domésticos, cargadores, vendedores de agua, choferes, sastres, carpinteros, mecánicos, plomeros, trabajadores de la construcción, guardias de seguridad, personal de restaurantes o bares, peluqueros, músicos, artesanos, escultores, recepcionistas, empleados de farmacia, dependientes de tiendas, maestros en escuelas o en clases particulares, fotógrafos, predicadores. También pueden dedicarse a la elaboración y venta informal de alimentos y al comercio informal.

Estas actividades constituyen la opción más accesible para los migrantes sin documentos, porque trabajos más formales o especializados normalmente requerirían que los refugiados regularizaran su situación, por ejemplo, obteniendo permisos de trabajo o permisos como pequeños comerciantes. En vista de las circunstancias, los migrantes tratan de explotar al máximo estas posibilidades, a través de redes y contactos. Sin embargo, las condiciones laborales en estas actividades suelen ser malas o incluso riesgosas, y los ingresos que se reciben a cambio son irregulares y muy bajos.

Para hacer frente a las difíciles condiciones de vida, los refugiados que se trasladan de manera irregular a las ciudades se apoyan. Al igual que sus pares en los campos, en las redes establecidas a nivel social. Dichas redes de apoyo se van creando en distintos ámbitos, desde el habitacional (el vecindario), el familiar o de amigos mutuos, las congregaciones religiosas, los sitios de trabajo y las escuelas.

Para los refugiados indocumentados, el grado de apoyo en estas distintas redes se irá transformando, dependiendo del tiempo que lleven en el espacio urbano. Inicialmente, la tendencia es que se busque apoyo sobre todo entre los familiares. Sin embargo, a medida que los migrantes permanecen más tiempo en la ciudad, es más frecuente que cuenten con el apoyo de redes en el espacio habitacional, o bien, en iglesias y mezquitas. ${ }^{90}$

\footnotetext{
${ }^{89}$ Mann, GlLlan, "Beyond war: 'suffering' among displaced Congolese children in Dar es Salaam", Development in Practice, vol. 22, núm. 4, 2012, p. 261.

${ }^{90}$ Willems, Roos, "Coping with Displacement: Social Networking among Urban Refugees in an East African Context", en Itaru Ohta y Gebre Yntiso (eds.), Displacement Risks in Africa: Refugees, Resettlers and their Host Populations,
} 
En algunos casos, estas redes son importantes desde el momento de la llegada, pues pueden ofrecer albergue temporal o ayudar a los recién llegados a encontrar un lugar para vivir. Son igualmente necesarias como fuente de oportunidades para extender el ámbito de socialización. También pueden actuar cuando el refugiado busca medios de subsistencia. A través de ellas, se pueden hacer arreglos que permitan a los recién llegados encontrar vías alternativas a los requerimientos oficiales de permisos o licencias para los negocios. Igualmente, los contactos en las redes pueden ayudar a los refugiados en situación irregular para adquirir nuevas habilidades profesionales. Finalmente, en períodos de especial dificultad, pueden constituir la vía para obtener apoyo económico. ${ }^{91}$

\section{Conclusiones}

El presente artículo pretende observar el papel activo que tienen los migrantes en los intentos por transformar su realidad. Ante la falta de derechos en los países receptores analizados, los migrantes han respondido de manera constante con iniciativas que buscan ampliar su capacidad de acción en distintos ámbitos. Asimismo, buscan potencializar el uso de los recursos con los que cuentan, muchas veces limitados. Incluso en las circunstancias sociales más adversas, los actores suelen encontrar ámbitos de oportunidad que tratan de aprovechar al máximo. Se desarrolla así un proceso constante de negociación entre los migrantes, las sociedades a las que llegan y los gobiernos.

Es difícil determinar con precisión el impacto de los intentos de empoderamiento por parte de los migrantes en las comunidades receptoras. Sin embargo, tanto en el caso de Sudáfrica como en el de Tanzania, se pueden constatar dos situaciones. En primer lugar, existe una continua tensión entre lo social y lo individual: los migrantes despliegan en forma incesante su capacidad de agencia y tratan de construir sus propias condiciones de vida, pero la estructura de oportunidades no siempre les resulta favorable.

En segundo término, las repercusiones de la actuación de los migrantes dependen de una serie de factores. Entre estos, destacan los niveles de concentración de migrantes (por ejemplo, si se trata de una población muy visible o fácilmente identificable), su capacidad de organización, el área donde se han

\footnotetext{
Australia, Trans Pacific Press, 2005, p. 62.

${ }^{91}$ Willems, Roos, "Coping with Displacement: Social Networking among Urban Refugees in an East African Context", en Itaru Ohta y Gebre Yntiso (eds.), Displacement Risks in Africa: Refugees, Resettlers and their Host Populations, Australia, Trans Pacific Press, 2005, p. 59.
} 
establecido y las condiciones de la población receptora concentrada en el área (su nivel de educación, sus ingresos y las condiciones sociales, entre otras). Influirá, igualmente, el grado de participación real de las autoridades, y el tipo de acciones que éstas tomen.

En algunos casos, los intentos de empoderamiento pueden ser relativamente exitosos. Un ejemplo claro es el de las zonas de influencia de los somalíes en Sudáfrica. A través de sus prácticas comerciales y culturales, estos migrantes han logrado introducir cambios en zonas determinadas de ciudades como Johannesburgo. No obstante, dichas transformaciones sólo son posibles cuando existe un cierto nivel de tolerancia hacia el otro por parte de la comunidad receptora. Incluso la falta de interés en la zona, por parte de la mayoría de la población local, permite que los migrantes se expandan con más libertad.

Sin embargo, con frecuencia se observa un desajuste entre las acciones de los migrantes y los resultados que obtienen: en muchos casos, las decisiones que toman de manera estratégica para obtener un beneficio pueden ser perjudiciales en el largo plazo. En Sudáfrica, eso ocurre por ejemplo con los migrantes que se asientan en zonas como Sunnyside, en Pretoria, o Hillbrow, en Johannesburgo. Ellos buscan insertarse en las redes sociales ya establecidas entre los migrantes, pero el resultado es que enfrentan problemas como el tráfico de drogas y las estafas. En el caso de Tanzania, el desajuste entre acción y resultado se aprecia con las migrantes que se prostituyen para obtener recursos económicos y de este modo continuar con su educación. En el corto plazo, pueden obtener dinero para pagar una colegiatura, pero el efecto a largo plazo será aumentar su vulnerabilidad.

El desajuste entre lo planeado y lo obtenido por los migrantes deja en claro que se necesitan otros elementos para estructurar de manera más sólida su capacidad de agencia. Una posible forma de lograrlo es pasar de lo meramente individual a lo colectivo. El proceso de empoderamiento de los migrantes debe incluir la toma de conciencia del lazo que existe entre sus intereses individuales y colectivos. Cuando el migrante se percata de que puede tener más fuerza si se une a un grupo que comparte sus mismos intereses ante situaciones adversas, es más probable que pueda hacer escuchar su voz, antes acallada por el miedo. Esto constituye un punto de inflexión fundamental, pues si bien la acción de una sola persona no provocará en sí misma una transformación de la estructura de oportunidades en los países analizados, la acción conjunta y continuada de diversos actores puede, en última instancia, contribuir al cambio.

Las redes a través de las cuales actúan los migrantes pueden ser un primer escalón para pasar de lo individual a lo social. Pero, a fin de potenciar el efecto 
de las acciones separadas, es conveniente el apoyo de otros agentes. Algunos grupos, como las onG, u organizaciones internacionales como el ACNUR podrían asumir este papel. Este tipo de organizaciones pueden ofrecer a las redes, establecidas por los propios migrantes, elementos que les permitan una acción más efectiva. Pueden, por ejemplo, ayudar en casos de ataques contra los migrantes, o brindar asesoría para que los migrantes demanden a las autoridades una mayor inclusión en las agendas de los gobiernos. Una colaboración de este tipo no implicaría necesariamente que los gobiernos actuaran inmediatamente a favor de los migrantes, pero se puede convertir en un factor importante de presión en la lucha por sus derechos.

En general, se puede considerar que la vinculación del migrante con las ONG y con organismos internacionales permite fortalecer su esfera de acción. No obstante, debe reconocerse que ese vínculo puede verse afectado por dos elementos. En primer lugar, por factores externos como la existencia -0 inexistencia- de fuentes de financiamiento para su operación en ciertas áreas geográficas. En segundo lugar, puede afectar el tipo de relación que exista entre ambas partes.

Para que los actores internacionales puedan emerger como el nexo entre la agencia de los migrantes y la estructura de oportunidades, se requeriría un replanteamiento de ciertas ideas centrales que han dado forma a las concepciones sociales sobre la migración. Ante todo, sería necesario precisamente reconocer la centralidad que los migrantes tienen en los procesos analizados.

En este proceso, se vuelve indispensable continuar con la tarea de investigar el fenómeno migratorio. Si bien este trabajo constituye un primer intento por entender el fenómeno de la construcción de la agencia de los migrantes, existen numerosas vertientes que se pueden retomar. De hecho, cada uno de los intentos de agencia de los migrantes constituye material que se puede utilizar para desarrollar otras líneas de investigación en contextos específicos.

\section{Bibliografía}

Amisi, Baruti y Ballard, Richard, "In the Absence of Citizenship: Congolese refugee struggle and organization in South Africa. A case of study for UKZN project entitled: Globalisation, Marginalisation and New Social Movements in post-Apartheid South Africa”, Durban, University of Kwazulu-Natal, 2005, pp. 3-6. [Consulta: 8 de octubre, 2016]. Disponible en: http://ccs.ukzn.ac.za/ files/Amisi\%20Ballard\%20Refugees\%20Research\%20Report.pdf 
Asylum Access TAnZAnia, No place called home. A report on urban refugees living in Dar es Salaam, Dar es Salaam, Asylum Access Tanzania, p. 7. Disponible en: http://asylumaccess.org/wp-content/uploads/2014/08/No-Place-Called-Home.pdf

BAKEWELl, Oliver, "Some Reflections on Structure and Agency in Migration Theory”, Journal of Ethnic and Migration Studies, vol. 36, núm. 10, 2010.

Cea D’Ancona, María Ángeles, "La exteriorización de la Xenofobia”, Revista Española de Investigaciones Sociológicas, núm. 112, octubre-diciembre, 2005.

Charman, Andrew y Peterson, Leif, “A Transnational Space of Business: The Informal Economy of Ivory Park, Johannesburg”, en Jonathan Crush, y Abel Chikanda (eds.), Mean Streets: migration, xenophobia and informality in South Africa, Ciudad del Cabo, Southern African Migration Programme - the African Centre for Cities - The International Development Research Centre, 2015.

Chaulia, Sreeram Sundar, “The Politics of Refugee Hosting in Tanzania: from Open Door to Unsustainability, Insecurity and Receding Receptivity”, Journal of Refugee Studies, vol. 16, núm. 2, 2003.

Ching'ole, Andrew Stanley, "Refugee and Development in Tanzania: An Exploration of benefits of Refugee Presence on Local Communities A case of North Western Tanzania”, Developing Country Studies, vol. 5, núm. 12, 2015.

CSFM-IRRI, "I don't know where to go", Burundian Refugees in Tanzania under Pressure to Leave, Dar es Salaam, Centre for the Study of Forced Migration-International Refugee Rights Initiative, 2009.

Crush, Jonathan, "South Africa: Policy in the Face of the Xenophobia”, Migration Policy Institute. [Consulta: 15 de octubre, 2016]. Disponible en: http://www. migrationpolicy.org/article/south-africa-policy-face-xenophobia

CRush, Jonathan, et al., "Migrant Entrepreneur and informality in South Africa", en Jonathan Crush y Abel Chikanda (eds.), Mean Streets: migration, xenophobia and informality in South Africa, Ciudad del Cabo, Southern African Migration Programme - African Centre for Cities - The International Development Research Centre, 2015.

Crush, Jonathan y Ramachandran, Sujata, "Chapter two. Doing Bussiness with Xenophobia”, en Jonathan Crush, y Abel Chikanda (eds.), Mean Streets: migration, xenophobia and informality in South Africa, Ciudad del Cabo, Southern African Migration Programme - the African Centre for Cities - The International Development Research Centre, 2015.

Crush, Jonathan y Tawodzera, Godfrey, "Medical Xenophobia and Zimbabwean Migrant Access to Public Health Services in South Africa”, Journal of Ethnic and Migration Studies, vol. 40, núm. 4, 2014, pp. 655657. [Consulta: 15 de noviembre, 2016]. Disponible en: http://dx.doi. org/10.1080/1369183X.2013.830504

Enwere, Corlivics Onuoha, Human rights and refugee protection in South Africa (1994-2004), Thesis, University of the Witwatersrand, 2006. 
Epstein, Gil y Gang, Iran, “Migration and Culture”, iza dp, núm. 5123, 2010, p. 3. [Consulta: 9 de octubre, 2016]. Disponible en: http://ftp.iza.org/dp5123.pdf "Exploring Tsonga Underground Money Transfer System-SA to Moz", Vivmag. [Consulta: 10 de octubre, 2016]. Disponible en: http://www.vivmag.co.za/ archives/ 10297

Fourchard, Laurent y Segatti, Aurelia, "Introduction of Xenophobia and Citizenship: the everyday politics of exclusion and inclusion in Africa", Africa, vol. 85, núm. 1, 2015.

Gumbo, Trynos, "Resilience and Innovation: Migrant Spaza Shops Entrepreneurs in Soweto, Johannesburg", en Jonathan Crush y Abel Chikanda (eds.), Mean Streets: migration, xenophobia and informality in South Africa, Ciudad del Cabo, Southern African Migration Programme - African Centre for Cities The International Development Research Centre, 2015.

Hlatshwayo, Mondl, "Xenophobia, Resilience, and Resistance of Immigrants Workers in South Africa: Collective and Individual Responses", en Aziz Choudry y Mondi Hlatswayo (eds.), Just Work? Migrant Workers's Struggles Today, Londres, Pluto Press, 2016.

IRIN, “ICVA warns against refugee repatriation from Tanzania”, 2002. Disponible en: http://www.irinnews.org/ar/node/199821

Jara, Mazibuko y Peberdy, Sally, "Progressive Humanitarian and Social Mobilisation in a Neo-Apartheid Cape Town: A Report on Civil Society and the May 2008 Xenophobic violence. Research Report”, The Atlantic Philanthopies, pp. 3537. [Consulta: 7 de octubre, 2016]. Disponible en: http://www.atlanticphilanthropies.org/app/uploads/2010/07/2_Cape_town_c.pdf

Kongeter, Stefan y Smith, Wendy, "Transnational Agency. Migrants, Movements and Social Support Crossing Borders", en Stefan Kongeter, y Wendy Smith (eds.), Transnational Agency and Migration: Actors, Movements, and Social Support, Nueva York, Taylor and Francis, 2015.

LANDAU, LoRen, "Beyond the Losers: Transforming Governmental Practices in Refugee Affected Tanzania”, Journal of Refugee Studies, vol. 16, núm. 1, 2003.

Legassick, Martin, "Gold, Agriculture and Secondary Industry in South Africa", en Palmer y Parson (ed.), The roots of rural poverty in Central and Southern Africa, University of California Press, 1977.

MaLKKI, LIISA, "Speechless Emissaries: Refugees, Humanitarianism, and Dehistoricization”, Cultural Anthropology, vol. 11, núm. 3, 1996.

Mann, Gillian, "'Finding a Life Among Undocumented Congolese Refugee Children in Tanzania", Children \&t Society, vol. 24, 2010.

Mann, Gillian, "Beyond war: 'suffering' among displaced Congolese children in Dar es Salaam”, Development in Practice, vol. 22, núm. 4, 2012.

MurRAY, Martin, "Alien Strangers in Our Midst: The Dreaded Foreign Invasion and Fortress South Africa”, Canadian Journal of African Studies, vol. 37, núm. 2-3, 2003. 
Mataure, Mandla, "Citizens Perception on Migration in South Africa”, Afrobarometer Briefing Paper, núm. 112. [Consulta: 5 de febrero, 2017]. Disponible en: http://afrobarometer.org/sites/default/files/publications/Briefing\%20 paper/afrobriefno112 2.pdf

ONU - OHCHR, Migration and human rights. Improving Human Rights-Based Governance of International Migration. Ginebra, oNU - OHCHR, 2013, pp. 7-8. Disponible en: http://www.ohchr.org/Documents/Issues/Migration/MigrationHR_improvingHR_Report.pdf

"R60m drug bust in Pretoria", Sowetan Live, 13 de septiembre, 2012. [Consulta: 9 de octubre, 2016]. Disponible en: http://www.sowetanlive.co.za/ news/2012/09/13/r60m-drug-bust-in-pretoria?filter=all_comments

Riger, StePhANIE, "What's wrong with empowerment”, American Journal of Community Psicology, junio de 1993.

Sadouni, SAmadia, "The stratified diasporas of Somalians", Mail \&t Guardian, 13 de febrero, 2015. [Consulta: 9 de octubre, 2016]. Disponible en: http://mg.co. za/article/2015-02-13-the-stratified-diasporas-of-somalians/

Samman, Emma y Santos, Maria Emma, Agency and Empowerment: A review of concepts, indicators and empirical evidence, Oxford, University of Oxford, 2009.

Solomon, Hussein, of Myths and Migration. Illegal immigration into South Africa, Pretoria, UNISA, 2003.

Sulaiman, Philip, "From Mogadishu to Mayfair: Somali diaspora finds home in Johannesburg”, Brand South Africa, 2016. [Consulta: 9 de octubre, 2016]. Disponible en http://www.mediaclubsouthafrica.com/africa/4459-from-mogadishu-to-mayfair-somali-diaspora-finds-home-in-johannesburg

"Tanzania: People cope with these tough living conditions because often they haven't known anything else", Médicos sin Fronteras, 9 de diciembre, 2015. [Consulta: 5 de febrero, 2017]. Disponible en: http://www.msf.org/en/article/tanzania-0E2\%80\%9Cpeople-cope-these-tough-living-conditions-because-often-they-haven\%E2\%80\%99t-known

Thomson, Marnie Jane, “Mud, Dust, and Marougé: Precarious Construction in a Congolese Refugee Camp”, Architectural Theory Review, vol. 19, núm. 13, 2014.

Turner, Simon, “Under the Gaze of the 'Big Nations': Refugees, Rumours and the International Community in Tanzania”, African Affairs, núm. 103, 2004.

VAN Hoyweghen, SASKIA, Mobility, territoriality and sovereignty in post-colonial Tanzania, ACNUR, octubre de 2001. Disponible en: http://www.unhcr.org/research/working/3bf101b37/mobility-territoriality-sovereignty-post-colonial-tanzania-saskia-van-hoyweghen.html

Vigaud Walsh, Francisca, "Women and girls failed: The burundian refugee response in Tanzania”, Refugees International, 22 de diciembre, 2015. [Consulta: 5 de febrero, 2017]. Disponible en: https://static1.squarespace. 
com/static/506c8ea 1e4b01d9450dd53f5/t/5678aee07086d7cddecf1bab/1450749707001/20151222+Tanzania.pdf

Wa Kwabe, Aurelia, "Reforming South African immigration policy in the post-apartheid period (1990-2006): what it means and what it takes", Wa Kwabe Segatti y Landau (eds.), Migration in post-apartheid South Africa: Challenges and questions to policy-makers, Research Department Agence Francaise de Developpement, 2008, p. 61. [Consulta: 27 de octubre, 2016]. Disponible en: http://www.afd.fr/jahia/webdav/site/afd/shared/PUBLICATIONS/RECHERCHE/Archives/Notes-et-documents/38-notes-documents-VA.pdf

Wentzel, Marie y Tlabela, Kholadi, Migration in South and Southern Africa. Dynamics and determinants, HSRC Press. [Consulta: 27 de octubre, 2016]. Disponible en: http://www.hsrcpress.ac.za/product.php?productid=2094Ctfreedownload=1

West, Amy y Wambugu, W. Lydia, Left to their own Devices. The Impact of Informal Information and Communication Networks on Security in the Tanzanian Refugee Camps, Londres, Article 19, 2003.

WiLlems, Roos, “Coping with Displacement: Social Networking among Urban Refugees in an East African Context”, en Itaru Ohta y Gebre Yntiso (eds.), Displacement Risks in Africa: Refugees, Resettlers and their Host Populations, Australia, Trans Pacific Press, 2005.

Women's Refugee Commission, The Path to Hope. Congolese Refugee Adolescent Girls in Nyarugusu Refugee Camp, Tanzania, Nueva York, Women's Refugee Commission, 2012. Disponible en: https://www.womensrefugeecommission. org/resources/document/868-the-path-to-hope-congolese-refugee-adolescent-girls-in-nyarugusu-refugee-camp-tanzania

"Why the Deadly Attacks Against Foreigners In South Africa Come As No Surprise", The Huffington Post, 26 de abril, 2015. [Consulta: 5 de febrero, 2017). Disponible en: http://www.huffingtonpost.com/2015/04/26/south-africa-xenophobic-attacks_n_7119816.html

ZACK, TANYA, "Making an Area Hot: Interrumpting Trade in an Ethnic Enclave in Johannesburg's Inner City", en Jonathan Crush y Abel Chikanda (eds.), Mean Streets: migration, xenophobia and informality in South Africa, Ciudad del Cabo, Southern African Migration Programme - African Centre for Cities The International Development Research Centre, 2015.

Zondi, Siphamandla, "Xenophobic Attacks. Towards and Understanding of Violence against African Immigrants in South Africa”, Africa Insight, vol. 38, núm. 2, 2008. 